\title{
Neuroinvasion in Prion Diseases: The Roles of Ascending Neural Infection and Blood Dissemination
}

\author{
Sílvia Sisó, Lorenzo González, and Martin Jeffrey \\ Veterinary Laboratories Agency (VLA-Lasswade), Pentlands Science Park, Bush Loan, Penicuik, Midlothian EH26 0PZ, UK \\ Correspondence should be addressed to Sílvia Sisó, s.siso@vla.defra.gsi.gov.uk
}

Received 30 October 2009; Accepted 8 March 2010

Academic Editor: Marylou V. Solbrig

Copyright ( 2010 Sílvia Sisó et al. This is an open access article distributed under the Creative Commons Attribution License, which permits unrestricted use, distribution, and reproduction in any medium, provided the original work is properly cited.

Prion disorders are infectious, neurodegenerative diseases that affect humans and animals. Susceptibility to some prion diseases such as kuru or the new variant of Creutzfeldt-Jakob disease in humans and scrapie in sheep and goats is influenced by polymorphisms of the coding region of the prion protein gene, while other prion disorders such as fatal familial insomnia, familial Creutzfeldt-Jakob disease, or Gerstmann-Straussler-Scheinker disease in humans have an underlying inherited genetic basis. Several prion strains have been demonstrated experimentally in rodents and sheep. The progression and pathogenesis of disease is influenced by both genetic differences in the prion protein and prion strain. Some prion diseases only affect the central nervous system whereas others involve the peripheral organs prior to neuroinvasion. Many experiments undertaken in different species and using different prion strains have postulated common pathways of neuroinvasion. It is suggested that prions access the autonomic nerves innervating peripheral organs and tissues to finally reach the central nervous system. We review here published data supporting this view and additional data suggesting that neuroinvasion may concurrently or independently involve the blood vascular system.

\section{Background}

Other than by direct invasion following traumatic and iatrogenic incidents, infectious agents can gain access to the brain by two mechanisms: using peripheral nerves as physical conduits (neural neuroinvasion) or via the blood (haematogenous neuroinvasion). Documented examples of the first include viruses, such as lyssaviruses or herpesviruses, and some bacterial infections such as listeriosis. Examples of the second include lentiviruses or flaviviruses and meningitides and thromboembolic encephalitides of bacterial aetiology.

The precise nature of the infectious agent of the transmissible spongiform encephalopathies (TSEs) or prion diseases is still to be determined, although the most widely accepted theory (the "protein-only" hypothesis) is that they are caused by an infectious proteinaceous agent. This agent, usually termed "prion" and often designated as $\mathrm{PrP}^{\mathrm{sc}}$, hypothetically originates as a result of an aberrant misfolding process of the cellular, normal host prion protein $\left(\mathrm{PrP}^{\mathrm{c}}\right)$. TSEs are a group of neurodegenerative disorders that can affect animals and humans and include, amongst others, scrapie in sheep and goats, bovine spongiform encephalopathy (BSE), chronic wasting disease (CWD) in cervids, transmissible mink encephalopathy (TME), and Creutzfeldt-Jakob disease (CJD) and its variant form (vCJD) in humans. Common to other protein misfolding neurological disorders, like Alzheimer's disease, TSE-affected individuals progressively accumulate disease-associated abnormal forms of $\mathrm{PrP}^{\mathrm{c}}$, generically designated $\mathrm{PrP}^{\mathrm{d}}$, in the brain and, in many instances, in other tissues. Regardless of the precise nature of the infectious agent, and although TSEs can be experimentally or iatrogenically reproduced by a variety of routes, it is believed that most natural infections are acquired by the alimentary route, so that the first barrier that the infectious agent encounters is the gastrointestinal epithelium. Once this barrier has been crossed, TSE agents could theoretically reach the brain by the same two pathways as any other infectious agent.

In this review we will present the findings that have led to the prevailing hypothesis of neuroinvasion in animal TSEs, that is, the neural route. We will also discuss whether such findings and recent data are compatible with an alternative or complementary pathway, that is, the haematogenous route. 
Emphasis will be laid on data from experimental TSE models in rodent species and sheep, although findings arising from natural infections in several species will also be considered.

One precaution to be taken when interpreting studies on pathogenesis is to consider carefully the techniques employed. In the case of TSEs, some of those studies, particularly early ones, were carried out by bioassay of selected tissues in laboratory animal species. While this approach is the only one that can demonstrate actual infectivity, it cannot determine which tissue structure or cell-type is infected because of the difficulties in fine dissection procedures and the risk of cross-contamination between tissues at necropsy. More recent and often comprehensive studies use $\operatorname{PrP}^{\mathrm{d}}$ as a surrogate marker of infection, albeit the correlation between the two is not always precise. The disease-specific form of the prion protein can be detected in the brain and viscera of TSE affected animals by a number of techniques, some of which, like ELISA or Western blot, employ extraction in detergents and incomplete enzymatic degradation to reveal protease-resistant $\operatorname{PrP}\left(\mathrm{PrP}^{\text {res }}\right)$. However, these techniques still lack definition of the precise structures harbouring the surrogate marker because sample dissection is done on fresh or frozen tissue. $\mathrm{PrP}^{\mathrm{d}}$ detected by immunohistochemistry (IHC) circumvents issues of potential contamination and can be precisely ascribed to specific tissues, structures, and cells, and even to the intra- or extracellular compartments. Moreover, IHC is able to detect diverse morphological types of $\operatorname{PrP}^{\mathrm{d}}$ which, depending on the protocol used, can include both protease-resistant and protease-sensitive forms. By using a panel of PrP antibodies, the integrity of the protein (full length or truncated, and their location) can also be determined.

\section{Neural Neuroinvasion: The Prevailing View}

2.1. Spread of Infectivity along Nerves. A number of studies have provided evidence in support of anterograde and retrograde transport of prion infectivity along peripheral nerves, and of transynaptic spread of infectivity within the central nervous system (CNS). The most easily interpretable paradigms arose from experiments based on cranial and peripheral nerve challenges. Thus, intraocular injection results in spread of infectivity along retinal ganglion axons and once within the brain follows transynaptic dissemination through the visual pathways $[1,2]$. Similarly, following intralingual inoculation, infectivity ascends rapidly and retrogradely via the XII cranial nerve reaching the hypoglossal nucleus within two weeks [3]. Curiously, evidence of transport along the olfactory nerves following intranasal exposure is still lacking $[4,5]$, and only the most recent experiments done by Bessen et al. [6] showed that only one hamster clinically affected out of five had traces of $\mathrm{PrP}^{\mathrm{d}}$ concomitantly within the olfactory sensory epithelium and in the glomerular layer of the olfactory bulbs. This result suggests that some transport of infectivity by olfactory nerves is possible although it is unclear if it would occur anterogradely from the CNS or retrogradely from the olfactory epithelium.
Estimates of the speed of axonal transport of prions vary from $0.5-3 \mathrm{~mm} /$ day along peripheral or cranial nerves, or within the central nervous system [7, 8]. Although these estimates face the significant confounding factor of the rate at which infectivity or $\operatorname{PrP}^{\mathrm{d}}$ is amplified or accumulated in the reporter cell or tissue, the data suggest that rates of spread of infectivity do not precisely correspond with either slow or fast axonal transport mechanisms. Nevertheless, neurotropic viruses also show a similar broad range of transport velocities; herpesviruses, for example, travel at rates of fast axonal transport [9], while the calculated velocity of rabies virus may be as low as $12 \mathrm{~mm} /$ day [10]. It is difficult therefore to conclude how prion infectivity may spread along neuronal processes simply from crude estimates of transport velocity.

The numerous intranerve transmission studies provide conclusive evidence that infectivity can be transported into the CNS along or within axons. There is also evidence that infection may also be transported out of the CNS along axons. Experimental rodent infections with the agents of scrapie and TME have shown that infection can spread from the thoracic segments of the spinal cord to their corresponding spinal [7] and to the sciatic [8] nerves. Similarly, intracerebral challenge of deer with cattle BSE results in $\operatorname{PrP}^{\mathrm{d}}$ in the enteric nervous system (ENS) in the absence of lymphoid tissue involvement and only after widespread $\mathrm{PrP}^{\mathrm{d}}$ accumulation in the brain [11]; such findings are most probably due to anterograde transport of infectivity from the CNS along nerve fibres.

2.2. Involvement of Lymphoid Tissues and Peripheral Nerves in TSEs. As early as 1967, studies of mouse scrapie after subcutaneous injection suggested that lymphoreticular system (LRS) tissues of hamsters such as the spleen and lymph nodes acquired infectivity prior to the brain [12]. In contrast, Kimberlin and Walker [13] did not find a similar role for the spleen when a different route was used. In those studies, intragastric administration of the scrapie strain 139A into mice concluded that agent replication in the Peyer's patches (PPs) occurred as fast as in the cervical lymph nodes, and earlier than in the spleen and CNS. Furthermore, splenectomy in those animals had no effect on incubation periods, in contrast to previous observations obtained after intraperitoneal inoculation with the same scrapie strain [14, 15]. These results, obtained in murine models, formed the pillars of the current neuroinvasion dogma, which suggests that after intraperitoneal infection neuroinvasion is initiated from the spleen and involves the sympathetic nervous system $[14,15]$, whereas neuroinvasion after intragastric infection is initiated directly from the intestines (via the PPs) and involves the enteric nervous system (ENS; [13]).

Several time course studies were initiated to investigate the spread of infectivity from the LRS to the CNS, [14, $16,17]$. Such studies reported a common neuroinvasion pathway for the intraperitoneal, intravenous (tail vein), and subcutaneous routes (scruff of the neck and foot pad), suggesting that neuroinvasion occurred through the spleen (and presumably visceral lymph nodes), along autonomic 
nerves such as the splanchnic nerves to the mid-thoracic spinal cord, from where it would disseminated gradually to the rest of the CNS (brain and lumbar spinal cord). Although direct evidence for the initial spleen-thoracic spinal cord pathway was lacking because of difficulties in sampling small autonomic nerves and ganglia in mice, indirect evidence based on detection of infectivity in the stromal fraction of the spleen, in which nerve endings are abundant, was provided [18]. At the same time, centrifugal spread from the spinal cord and brain to peripheral nerves was demonstrated $[7,19]$.

Working with orally or intraperitoneally inoculated hamsters, Baldauf et al. [20] provided strong evidence for an alternative route of access of the $263 \mathrm{~K}$ strain to the brain that bypassed the spinal cord. It was proposed that the fibres of the vagus nerve would be the most likely direct pathway, although other cranial nerves and a blood- or even a cerebrospinal fluid- (CSF-) borne access were not ruled out. Similar to previous data obtained by Western blot analysis [21], spleens of infected hamsters did not consistently show PrPres thus questioning mandatory lymphoid tissue replication prior to neuroinvasion. Further evidence from experimental scrapie rodent models [2226] confirmed the early involvement of the enteric and abdominal ganglia not only by doing infectivity assays but also by detecting the $\mathrm{PrP}^{\mathrm{d}}$ by IHC or paraffin-embedded tissue blot. Spatio-temporal studies on $\mathrm{PrP}^{\mathrm{d}}$ deposition revealed that the dorsal motor nucleus of the vagus nerve (DMNV) and the intermediolateral columns (IMLC) of the thoracic spinal cord were the first two CNS target sites to accumulate $\operatorname{PrP}^{\mathrm{d}}$. These authors suggested that the infectious agent reached the CNS retrogradely from the ENS by two different circuits: the splanchnic nerves circuit and the vagus nerve circuit as illustrated in Figure 1. The splanchnic circuit involved the cranial mesenteric and celiac ganglia and the IMLC followed by the dorsal root ganglia. The vagus nerve circuit involved the DMNV by passing the nodose ganglion. Subsequent experiments demonstrated the presence of infectivity in the vagus nerve and the cranial mesenteric ganglia by hamster bioassays [22].

Using $263 \mathrm{~K}$ infection of hamsters, Diringer [27] described a low level of "viraemia" lasting for at least 40 days, with detectable amounts of infectivity in the CNS, purportedly in capillary endothelial cells, but no sustained replication elsewhere. Experiments using the same hamster scrapie model discouraged consideration of haematogenous dissemination of infectivity by describing replication in the spleen and thoracic spinal cord earlier than in the brain $[14,28]$. Evidence for a high and persistent "viraemia" was only available for some specific TSE models, such as the K.Fu strain of CJD in mice [29]. Similar to experiments in mice, the topographical $\mathrm{PrP}^{\mathrm{d}}$ distribution using the hamster model of $263 \mathrm{~K}$ did not reveal any evidence for haematogenous spread of infection to the brain [22]. Consequently, neuroinvasion in most studied rodent TSE models was thought to be crucially dependent on a non-blood-related compartment connecting the lymphoid tissue and the CNS, that is, the peripheral nervous system (PNS).

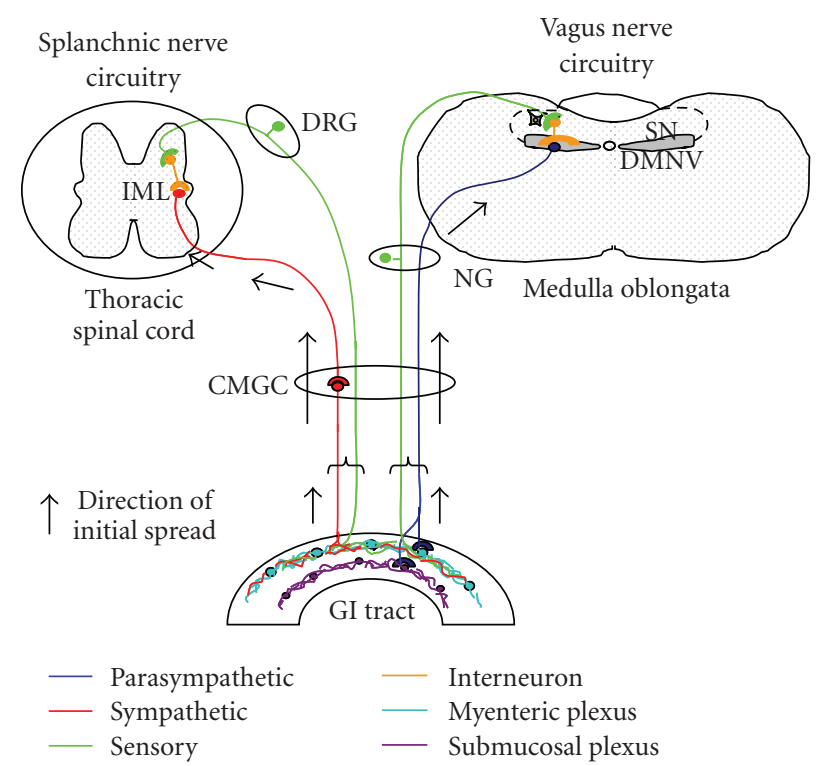

FIGURE 1: Schematic representation of the most generally accepted hypothesis of the routes of neuroinvasion in TSEs. Permission was obtained for reproducing this figure originally published in [22]. DRG, dorsal root ganglia; NG, nodose ganglion; CMGC, celiac and mesenteric ganglion complex; GI tract, gastrointestinal tract.

\subsection{Support to Neural Neuroinvasion Gained from Transgenic} and Mutant Rodent Models. An important contribution towards determining neuroinvasion pathways has been the use of transgenic, knockout, or mutant mice. From the early 1990s, such approaches have emphasised the role of key immune cell components in the up-take and replication of infectivity in the periphery and their contribution in transporting infectivity to the CNS [26]. In this respect, Klein et al. [30,31] found no effect on susceptibility to disease or on spleen infectivity when mice deficient in T-lymphocytes were challenged with scrapie. In contrast, neuroinvasion was impaired in mice that were immunodeficient only in B-lymphocytes. Further investigations using scrapie-infected $\mathrm{TNF}^{-/-}$mice lacking mature follicular dendritic cells (FDCs) but not B lymphocytes [32, 33] concluded that accumulation of infectivity and $\mathrm{PrP}^{\mathrm{Pres}} / \mathrm{PrP}^{\mathrm{d}}$ in spleen and subsequent neuroinvasion were dependent upon mature FDCs. Parallel research towards investigating the role of macrophages in TSE pathogenesis concluded that macrophages were involved in the clearance of infectivity [34]. Complementary studies using transgenic mice overexpressing $\mathrm{PrP}^{c}$ highlighted the importance of determining $\mathrm{PrP}$ interacting molecules or receptors which might be crucial for the normal function of FDCs and the interaction with B cells [26]. Although extensive research has focused on FDCs as cells for prion replication, current research highlights the role of dendritic cells, B-cells and macrophages in the transfer of infectivity from the gut to lymphoid organs $[35,36]$.

It is the interpolations between data obtained from all different animal models that have led to the most accepted view on absorption and transport of the infectious agent to the autonomic nervous system after oral exposure to 


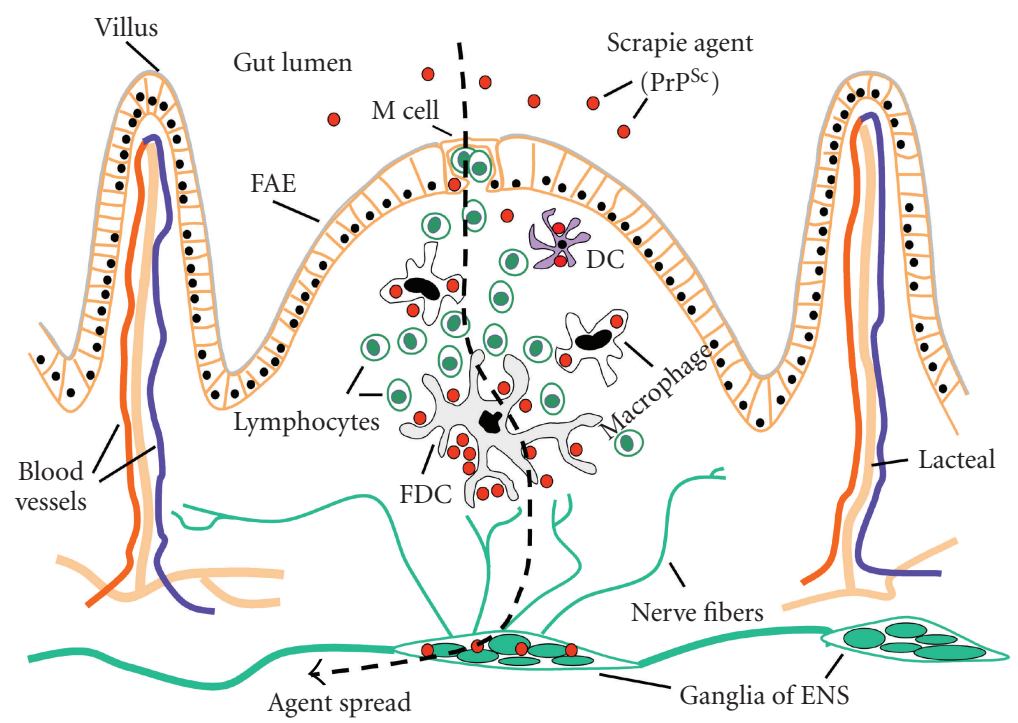

FIGURE 2: Diagrammatic representation of the possible pathways of absorption of TSE agents from the gut lumen and their transport to the ENS. Permission was obtained for reproducing this figure originally published in [26].

prions. Figure 2 provides a diagrammatic representation of the possible ways by which the ENS can become infected after oral/intragastric exposure. Many studies have focused on the role of $\mathrm{M}$ cells [25], dendritic cells [37], and possibly enteroendocrine cells as important candidates for the uptake or absorption of infectivity from the gastrointestinal tract. The infectious agent would then be transported to the lymphoid follicles of the PPs, where it would replicate in a B-cell and FDC-dependent manner. Subsequently, infectivity would reach nerve endings in and around the follicles and retrograde transport of the infectious agent would occur from the nerve endings towards the neuronal somata of the submucosal and myenteric plexuses. Alternatively, the agent could be transported from the gut lumen through the absorptive epithelium of the villi and could infect nerve endings of the lamina propria before being transported to the enteric plexuses [39].

Further support for the role of enteric neurons in the disease is their high $\operatorname{PrP}^{c}$ mRNA levels [40]. In parallel, several rodent models have been produced in order to further support the idea that sympathetic nerves are responsible for transporting infectivity from the spleen to the spinal cord. Apparently this transfer of infectivity, which is facilitated in highly innervated spleens (as reviewed by [41]), occurs in a $\mathrm{PrP}^{\mathrm{c}}$-dependent fashion [42] and its rate is limited by the splenic sympathetic innervation [43]. The fact that mice with hyperinnervated spleens showed shorter incubation periods and higher infectivity titres and $\operatorname{PrP}^{\mathrm{d}}$ accumulation $[43,44]$ supports this statement, whereas the fact that denervated mice still develop scrapie [41] and, similarly, the failure of splenectomy to prevent disease implies that alternative routes participate in the neuroinvasion process and that spleen innervation might not be a prerequisite. In this respect, a major role of parasympathetic nerve fibers like the vagus nerve has been suspected for decades. However, similar evidence supporting the role of the vagus nerve in the pathogenesis of prion diseases is lacking as data from vagotomised rodent models is not available.

2.4. Neuroinvasion in Experimental Sheep Models. The first studies on sheep scrapie pathogenesis date back to the late 70s, at which period bioassay in rodents was the only tool available to test for the presence of infectivity in non-CNS tissues. Using such tools Hadlow et al. [45, 46] demonstrated that scrapie infectivity replicates in the PPs and other secondary lymphoid tissues before reaching the CNS. Interestingly, blood was postulated as the vehicle of infection for those peripheral LRS tissues, even though no infectivity was detected in blood from naturally scrapieinfected sheep at the time. Later, sheep experiments traced infectivity by $\mathrm{PrP}^{\mathrm{d}}$ or $\mathrm{PrP}^{\mathrm{res}}$ detection, [47-51] implicating, in addition to the PPs and other LRS tissues, the PNS, and the ENS in the spread of infectivity to the CNS.

Cell types supporting infectivity and $\mathrm{PrP}^{\mathrm{d}}$ accumulation are generally found throughout all lymphoid tissues, with the exception of the thymus, and usually also in neurons of the ENS [49, 53-55]. $\mathrm{PrP}^{\mathrm{d}}$ accumulation in LRS tissues is found in association with mature FDCs of the light zone and tingible body macrophages (TBMs) of the light and dark zones of secondary follicles (Figure 3). Ultrastructural studies confirmed that $\operatorname{PrP}^{\mathrm{d}}$ within the germinal centre of follicles locates mainly in association with the plasma membrane of FDCs and lysosomes of TBMs [56]. At early stages of infection, $\mathrm{PrP}^{\mathrm{d}}$ has been associated with dendritic cells or macrophages in the dome of the PPs in addition to cells of lymphoid tissues [53] or in the lacteals [38, 39]. The demonstration of initial $\mathrm{PrP}^{\mathrm{d}}$ accumulation in the gutassociated lymphoid tissue (GALT) and tonsil $[49,53]$ of sheep with preclinical natural scrapie strongly supported the hypothesis of infectivity crossing the mucosal barrier of the gastrointestinal tract by M-cell transcytosis followed by dendritic cell/macrophage transport, as illustrated in Figure 2. 


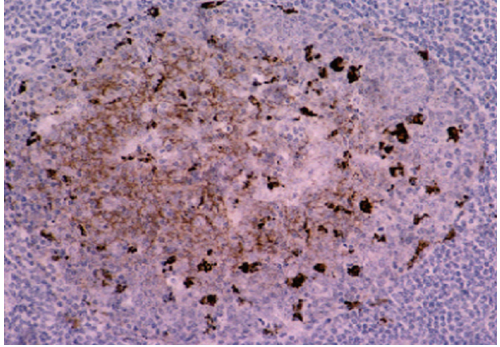

(a)

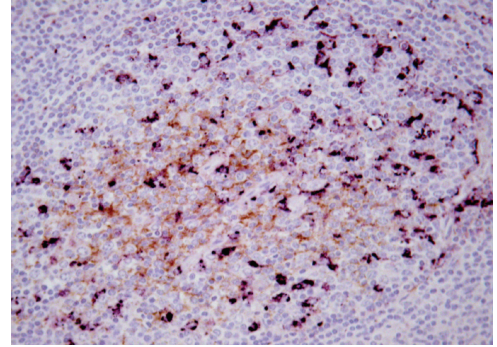

(b)

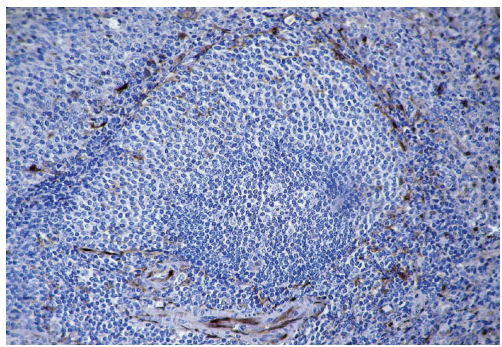

(c)

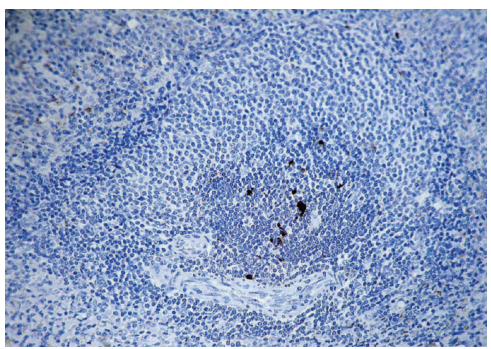

(d)

FIgURE 3: Scrapie infection in lymphoreticular tissues in ARQ/ARQ Suffolk sheep. (a) PrPd accumulation is associated with both FDC and macrophages in clinically affected sheep as shown by single IHC for PrP antibody R145. Peyer's patches of the distal ileum. (b) PrP ${ }^{\mathrm{d}}$ within TBMs is $\mathrm{N}$ terminally truncated whereas $\mathrm{PrP}^{\mathrm{d}}$ associated with FDC is not [52]. TBM and FDC can be distinguished in tissue sections by using $\mathrm{N}$ or $\mathrm{C}$ terminal PrP antibodies. FDCs (brown), labelled by the $\mathrm{N}$ terminal antibody FH11, are in light zone whereas TBMs (purple), labelled by the $\mathrm{C}$ terminal antibody R145, are both in dark and light zones of secondary lymphoid follicles: double IHC for FH11 (brown, DAB substrate) and R145 (purple, VIP substrate). In spleen, nerve endings located in the marginal zone ((c), IHC for PgP9.5) do not colocalised with $\operatorname{PrP}^{\mathrm{d}}$ deposition ((d), IHC for R145). (a)-(d) x20.

In a series of experiments, van Keulen and colleagues described the temporal spread of $\operatorname{PrP}^{\mathrm{d}}$ accumulation, in the GALT, non-GALT LRS, ENS, PNS, and CNS. They postulated that scrapie pathogenesis occurred in three different phases (Figure 4). In the first phase, after oral exposure to infection, the scrapie agent would be taken up by $\mathrm{M}$ cells followed by trancytosis to dendritic cells or macrophages, which would transport infection towards the secondary lymphoid follicles of the PPs and then drained to regional lymph nodes. A second phase of lymphatic dissemination would take place once infectivity is circulating the lymph (and blood) and therefore non-GALT LRS tissues would become involved. The fact that most data available on LRS examinations in sheep scrapie models describe infectivity of all lymphoid tissues at more or less the same time is highly suggestive of blood being an early contributing factor to dissemination of infection. Finally, neuroinvasion would arise in a third phase as a result of infection of nerve endings in the gut, GALT, and non-GALT LRS tissues and its retrograde spread through sympathetic and parasympathetic pathways.

Several sheep studies, encompassing sheep of different PrP genotypes, agree on the ENS being the first neural tissue in which $\operatorname{PrP}^{\mathrm{d}}$ can be demonstrated $[49,51,57,58]$. In the latter study, the authors identified the duodenum and ileum as the initial ENS sites to accumulate $\mathrm{PrP}^{\mathrm{d}}$ and suggested subsequent spread towards the upper and lower gastrointestinal tract [51]. Infection of the different plexuses of the ENS could arise from various origins ([59]; reviewed by [60]): (i) fine nerve fibres underneath the villous epithelium could bring infection to the submucosal plexus; (ii) nerve endings at follicles of the PPs could also take infection to the submucosal plexus, (iii) indirect contact by means of lymph or active transport between the PPs and the ENS. In other studies, Heggebø et al. $[59,61]$ demonstrated $\mathrm{PrP}^{\mathrm{d}}$ accumulation in the marginal zone of the spleen, which is a highly innervated area. Therefore, as suggested for rodent models, retrograde transport from sympathetic nerve fibres connecting the spleen with the spinal cord could support neuroinvasion in sheep scrapie. Interpretation from all these studies postulated that entry to the DMNV was either by a retrograde spread of $\mathrm{PrP}^{\mathrm{d}}$ from the ENS along efferent parasympathetic fibres of the vagus nerve or by anterograde spread from other nuclei such as the nucleus of the tractus solitarii. The fact that neurons of the trigeminal and nodose ganglia accumulate $\mathrm{PrP}^{\mathrm{d}}$ later than the brain [51] would suggest that these ganglia become affected as a result of descending transport.

The interval between infection and first $\mathrm{PrP}^{\mathrm{d}}$ detection in peripheral tissues of naturally exposed sheep will depend on age of exposure and dose but experimental data show that strain and genotype also markedly influence rates of $\mathrm{PrP}^{\mathrm{d}}$ accumulation. Sheep of ARQ/ARQ genotype naturally infected with scrapie or experimentally infected with BSE $[54,55]$ accumulate $\operatorname{PrP}^{\mathrm{d}}$ in LRS tissues more slowly than do naturally or experimentally exposed VRQ/VRQ sheep $[49,53]$. It is not clear whether these effects are solely strain or genotype effects or a combination of both. 


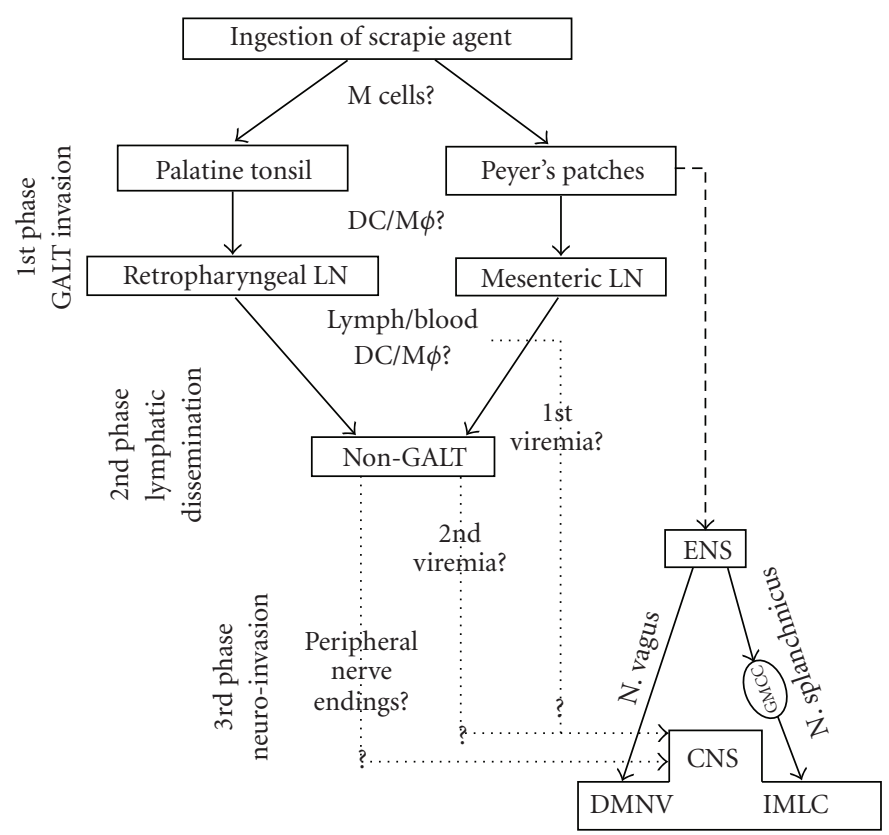

FIgURE 4: Pathogenesis of sheep scrapie. Permission was obtained for reproducing this figure originally published in [53]. For abbreviations see text.

Comprehensive pathogenetic studies have been performed on sheep infected with BSE, including infectivity assays [62] and tissue distribution of $\mathrm{PrP}^{\mathrm{d}}$ deposition by immunohistochemistry $[55,60,62,63]$. Despite spatiotemporal differences reported between them, these studies complement each other as all had in common the type of inoculum, dose, and host PRNP genotype. Bellworthy et al. [62] demonstrated BSE infectivity in a wide range of tissues of ARQ/ARQ sheep including the PPs as early as 4 months postinfection, the spleen at $10 \mathrm{~m}$ after dosing, and other LRS tissues, CNS, and liver at $16 \mathrm{~m}$ postinoculation. In common with rodent studies, bioassay detecting infectivity was more sensitive than IHC in detecting presence of $\mathrm{PrP}^{\mathrm{d}}$. Resistance to oral BSE infection was observed in sheep of ARQ/ARR and ARR/ARR PRNP genotypes, which can be overcome if the intracerebral route is used [64], although the resulting magnitude of $\mathrm{PrP}^{\mathrm{d}}$ accumulation is lower than in ARQ/ARQ sheep inoculated by the same route [63], and LRS dissemination is only observed in sheep of the last genotype [65]. Importantly, no influence of the genotype or of the route of inoculation was observed on the signature of the BSE agent in terms of intracellular truncation of BSE $\operatorname{PrP}^{\mathrm{d}}$ and proteinase-K cleavage site of BSE PrPres. These experiments suggest that the pathogenesis of experimental sheep BSE can differ depending on the route of inoculation and the host PRNP genotype.

Van Keulen et al. [60] showed the progressive accumulation of $\mathrm{PrP}^{\mathrm{d}}$ in 11 sheep orally dosed with cattle BSE and killed at 6 months postinfection and thereafter at 2-3-month interval. As with natural scrapie in VRQ/VRQ sheep, BSEinfected ARQ/ARQ Texel sheep developed clinical disease after peripheral accumulation of $\operatorname{PrP}^{\mathrm{d}}$ within the lymphoid tissues and autonomic nervous system. The first LRS tissues to accumulate $\operatorname{PrP}^{\mathrm{d}}$ were the GALT, followed by the GALTdraining lymph nodes and the spleen, and at a later stage, the non-GALT lymph nodes. Similar data were found in an earlier study albeit with some subtle differences. Jeffrey et al. [54] described first involvement of the retropharyngeal lymph nodes prior to the PPs in Romney sheep at 4 months post infection. Furthermore, $\mathrm{PrP}^{\mathrm{d}}$ deposition in CNS with no apparent LRS or PNS involvement up to 22 months postinoculation was observed in $40 \%(2 / 5)$ of clinically sick sheep [55]. In the Texel sheep, by 9 month postinoculation, $\mathrm{PrP}^{\mathrm{d}}$ was present in ENS neurons followed by the coeliacmesenteric ganglion and the first two target sites in the CNS: the IMLC in the T7-L1 segments of the spinal cord and the DMNV in the brain. By 12-13 months dissemination to all non-GALT tissues had taken place. Colocalization of $\mathrm{PrP}^{\mathrm{d}}$ and CD68-positive macrophages was apparent in the marginal zone of spleen, suggesting a possible active trapping and phagocytosis of $\mathrm{PrP}^{\mathrm{d}}$ from circulating blood with potential for neuroinvasion as this is a compartment highly innervated by sympathetic autonomic fibres (Figure 3(c)). From 12-13 months postinoculation onwards spread within the ENS and IMLC affected all gastrointestinal tissues examined and all thoracic and lumbar spinal cord levels, respectively. It was not until 19 months postinoculation that sheep showed clinical signs of disease and $\mathrm{PrP}^{\mathrm{d}}$ deposition in the cerebral cortex.

2.5. Neuroinvasion in Other Natural TSEs. The mechanism of neuroinvasion in cattle affected with BSE remains uncertain. Although $\mathrm{PrP}^{\mathrm{d}}$ accumulation [66] and infectivity [66-70] has been reported in the GALT and ENS of cows orally challenged with exceedingly high doses of BSE, in natural BSE cases there is no known involvement of any viscera 
or the PNS. A recent report of two animals that were part of a sequential kill experiment after oral exposure to a high dose of BSE agent concluded that BSE infectivity is retrogradely transported from the gastrointestinal tract to the CNS by two pathways [71]: (i) via the coeliac and mesenteric ganglion complex, through the splanchnic nerves towards the thoracolumbar spinal cord, and (ii) via the vagus nerve. Such conclusions arise from finding $\operatorname{PrP}^{\mathrm{d}}$ accumulation within the DMNV, coeliac and caudal mesenteric ganglia, and spinal cord segments but only in one of the reported cows. In this same experiment, authors anticipated that the presence of $\mathrm{PrP}^{\mathrm{d}}$ in the CNS prior to the dorsal root ganglia and possibly other peripheral nerves, that is, sciatic nerve, could be due to a secondary retrograde spread from the periphery to the CNS. Although the authors suggested a neural rather than lymphoreticular neuroinvasion-based pathway, importantly, none of the two cows had ENS involvement or showed $\mathrm{PrP}^{\mathrm{d}}$ in the vagus nerve even though several sections were examined.

The pathogenesis of CWD in cervids seems to vary between elk and deer [72]. Lymphoreticular dissemination occurs in preclinically affected deer but neuroinvasion has been reported in elk with no LRS involvement (reviewed by [73]). It is suspected that such differences might be partially defined by the species and the PRNP genotype. Accumulation of $\operatorname{PrP}^{\mathrm{d}}$ in the PNS has been demonstrated in mule deer with CWD [74], suggesting a similar pathogenesis to that reported for small ruminants with scrapie.

The mechanisms of neuroinvasion in transmissible mink encephalopathy (TME) have been extensively investigated in hamster models. Early studies described two biologically distinct strains in hamsters infected with TME, the hyper (HY) and the drowsy (DY) strains [75]. Both strains cause neuropathology in the CNS but only the HY disseminates within the LRS compartment. In a large number of experiments and using a variety of routes, Bartz et al. $[3,8,76]$ have demonstrated that LRS involvement is not required for prion neuroinvasion, and that it occurs via peripheral or cranial nerves. Recent investigations [6] conclude that neuroinvasion is dependent on LRS involvement for specific routes of entry such as the nasal cavity but not for others such as the tongue (oral cavity). These different routes of ascending infection result in different CNS targeting [76].

For obvious reasons, the pathogenesis of CJD in the natural host is the least studied amongst prion diseases. The pathogenesis of sCJD differs from that of vCJD. Accumulation of $\mathrm{PrP}^{\mathrm{d}}$ is widespread in neural and lymphoreticular tissues in vCJD, whereas it is mostly restricted to the CNS in sCJD [77]. Consequently, tonsil and spleen biopsies are optimal tissues for preclinical vCJD diagnosis. Deposition of $\mathrm{PrP}^{\mathrm{d}}$ in the posterior roots of spinal cord with absence of ENS involvement in SCJD patients is thought to be due to centrifugal spread of infectivity [78]. Interestingly, some sCJD patients with prolonged clinical periods displayed detectable $\mathrm{PrPres}^{\mathrm{r}}$ in skeletal-muscle and spleen homogenates by Western blot analysis [79]. Unfortunately, no IHC examination was performed in those positive samples. Thus $\mathrm{PrP}^{\text {res }}$ deposition found in muscles could have been associated with peripheral nerves, muscle spindles, or myocytes and in spleen may have been associated with peripheral nerves or lymphoid follicles.

2.6. Caveats in the Prevailing View of Neural Neuroinvasion. Although the onset of $\mathrm{PrPd}^{\mathrm{d}}$ accumulation in the LRS generally occurs significantly before that in the CNS, the consistency and time of appearance of such depositions varies depending on age, PRNP genotype, TSE strain, or source and route of inoculation. Thus, it is known that lymphoid follicles of the GALT undergo involution with age, and this is believed to have an effect on susceptibility to infection after oral exposure. In the case of TSEs, however, it has been shown that such physiological involution may be modulated by the infection itself, so that it does not seem to occur in the GALT that accumulates $\operatorname{PrP}^{\mathrm{d}}[66,80,81]$. As far as the PRNP genotype is concerned, some earlier studies [82, 83] described lack of, or minimal, involvement of LRS tissues in sheep of the VRQ/ARR and VRQ/ARQ PRNP genotypes naturally infected with scrapie. Equally, a small proportion of scrapie-infected goats (4/72) were found to accumulate $\mathrm{PrP}^{\mathrm{d}}$ only in the brain and not in any of 10 LRS tissues examined; all those four animals carried the methionine allele at codon 142 [84]. Examples of the effect of the TSE agent strain or source include natural BSE [69], sporadic CJD [85], experimental CH1641 infection of sheep [38, 39], and Nor-98 [86], in all of which $\operatorname{PrP}^{\mathrm{d}}$ accumulates in the CNS without prior replication in LRS tissues. Therefore, to explain the neural neuroinvasion pathway, infection of the ENS and other nerve terminals of the autonomic nervous system would have to occur without previous LRS amplification.

Replication of infectivity in the GALT and non-GALT LRS tissues may often be demonstrated early in the disease process. However, nerve endings in such tissues may not necessarily become infected or if infected may not result in retrograde transport to the CNS. Peripheral nerve terminals can be found in the PPs of the intestine and could pick up infectivity by contact with $\mathrm{PrP}^{\mathrm{d}}$-containing TBMs and FDCs. However, while a rich network of nerves is present in the T-cell areas of the PPs-in which there is no $\operatorname{PrP}^{\mathrm{d}}$ accumulation-, nerves are very rarely found in the secondary follicles $[59,80,87,88]$, where FDCs, the principle cells which amplify infection in viscera, are located. Similarly, nerves cannot readily be detected in secondary follicles of other LRS tissues, particularly lymph nodes, and it is therefore difficult to see how infectivity could be transferred from the LRS to the PNS. Moreover, morphological analysis in confocal microscopy concluded that neuroimmune connections in PPs, spleens, and mesenteric lymph nodes from preclinical scrapie infected mice are established between dendritic cells in T-cell areas and peripheral nerves rather than arising from FDC in B-cell areas [36]. Although ovine noradrenergic fibres are relatively close to FDCs in the spleen $[89,90]$, no direct contact has been established, and patterns of immunolabelling for $\mathrm{PrP}^{\mathrm{d}}$ resembling nerve-like structures have not been reported. Innervation of lymphoid tissues is affected by the age-related involution process [91], so that a general increase in nerve density of the intestine 
during early phases of life may contribute to an increased susceptibility of young animals to oral infection [80].

Following subcutaneous challenge, scrapie infectivity may reach the local lymph nodes via the afferent drainage and leave via efferent drainage to reach the blood. Recent studies done in sheep indicate that infectivity reaches the contra-lateral lymph nodes and lymph nodes distant to the site of inoculation almost as quickly as the ipsi-lateral nodes, suggesting that all of them were exposed more or less simultaneously (Chianini et al. unpublished observations). Similarly, naturally and orally challenged sheep with scrapie generally show early and widespread involvement of all LRS, including those that drain the head or limbs and are not anatomically linked to the alimentary system. The speed with which all lymph nodes become infected is not consistent with one lymph node or a group of lymph nodes being initially infected and subsequently amplifying infectivity for spread to other nodes.

The transcytosis and absorption of $\mathrm{PrP}^{\mathrm{d}}$ within a scrapie brain homogenate placed within the gut lumen was followed across the gut mucosa of sheep using IHC. $\operatorname{PrP}^{\mathrm{d}}$ within the homogenate was rapidly translocated (within 15 minutes) to mucosal and submucosal lymphatics [39]. From such a location infectivity would rapidly reach the vascular system. In this experiment no evidence to support transport of the homogenate across the dome and thus directly into PPs could be found; yet this model produced accelerated infection of PPs resulting in $\operatorname{PrP}^{\mathrm{d}}$ accumulation within 30 days, compared with more than 8 months for the corresponding natural disease. Thus, another possibility would be that germinal centres of LRS tissues are most exposed to infectivity via blood.

A recent study conducted on 67 preclinically infected sheep exposed to natural or experimental scrapie or BSE by various routes (oral, subcutaneous, intracerebral, or intravenous) showed that, regardless of the route, initial $\mathrm{PrP}^{\mathrm{d}}$ accumulation consistently occurred in the DMNV followed by the hypothalamus [92]. These findings are difficult to reconcile with a unique neuroinvasion ENS/PNS axis pathway. An alternative explanation would be that infection, which is present in blood, reaches the vagus nerve from its terminals in any organ or tissue compartment. Head et al. [93] have published the topographical brain distribution of amyloid plaques and lesion profiles of a linked human blood donor (orally infected) and blood recipient (intravenously infected). An almost identical severity and distribution of plaques and vacuoles were found both in donor and recipient thus supporting a common CNS portal of entry regardless of the route of exposure.

\section{Haematogenous Neuroinvasion: The Alternative Hypothesis}

3.1. Evidence for Infectivity in the Blood. Despite the fact that intravenous infection systematically resulted in shorter incubation periods than the intraperitoneal and subcutaneous routes, Kimberlin and Walker [16] were unable to find evidence of blood infectivity by bioassay. However, after further studies with the same 139A scrapie strain, a short "viraemic" phase immediately after injection was observed, leading Millson et al. [94] to conclude that the haematogenous spread of the agent was the likely means by which infection spread to the spleen and lymph nodes. Subsequent rodent blood bioassay experiments showed that a "viraemic" or "prionaemic" phase was evident early in the incubation period [27]. In the case of infection taking place by the oral route, it has been proposed that prionaemia could take place in two phases: an early one immediately after cell-mediated or cell-free uptake of infection from the gut lumen into the lymphatic system, and a second phase after amplification in LRS tissues [92].

An important series of experiments directed towards establishing the risk of transmission from blood products have provided the most comprehensive data on the presence of infectivity in blood. Infectivity demonstrated in the blood of BSE-infected sheep [92, 95, 96, 99], of natural scrapie cases $[95,100,101]$, and of CWD-infected deer [102] agrees with data suggesting that vCJD can be transmitted by blood transfusion from donors incubating the disease. Descriptions of five transfusion-related vCJD cases have confirmed transmission of infection by blood-derived products [103107]. Moreover, sheep experiments have shown that scrapie and BSE may be transmitted with blood collected early in the incubation period, even before any other evidence of infection is apparent $[92,95,96]$, although the likelihood of transmission increased together with the incubation period in the blood donors. This would imply that infectivity in blood is an early and permanent (maybe even progressive) event rather than a transient one, in contradiction with the results on PrPres detection in the blood of hamsters by protein misfolding cyclic amplification [108].

\subsection{Evidence That Infectivity in Blood May Establish Tissue} Infection. Haematogenous dissemination of infection may have relevance for more than one aspect of TSE pathogenesis. Experiments with blood transfusions in sheep demonstrated how the route, oral (BSE donors) versus intravenous (BSE recipients) can affect peripheral pathogenesis (Figure 5). Although a similar scenario might be predicted for vCJD, it remains to be established if spleens of vCJD patients infected after receiving blood fractions contain higher $\mathrm{PrP}^{\mathrm{d}}$ magnitudes than those from patients infected by consumption of BSE-contaminated products. Accumulation of $\operatorname{PrP}^{\mathrm{d}}$ can be demonstrated in placenta [109], mammary gland [110], salivary glands [111], and kidney [96, 97, 112] of TSEaffected sheep. In the latter, with both scrapie [112] and BSE (S. Sisó, personal observations) infections, $\operatorname{PrP}^{\mathrm{d}}$ can be detected in mesenchymal cells between collecting ducts and loops of Henle in the renal pelvis in the absence of inflammation, suggesting that mesenchymal cells become infected from blood after filtration in the glomeruli or by extravasation from the vasa recta. Also in sheep, $\mathrm{PrP}^{\mathrm{d}}$ in the mammary gland $[110,113]$ and infectivity in milk $[113,114]$ also most probably derive from the blood, as it does in scrapie-affected goats, in which accumulation of $\operatorname{PrP}^{\mathrm{d}}$ in the mammary gland only occurred in animals with widespread 


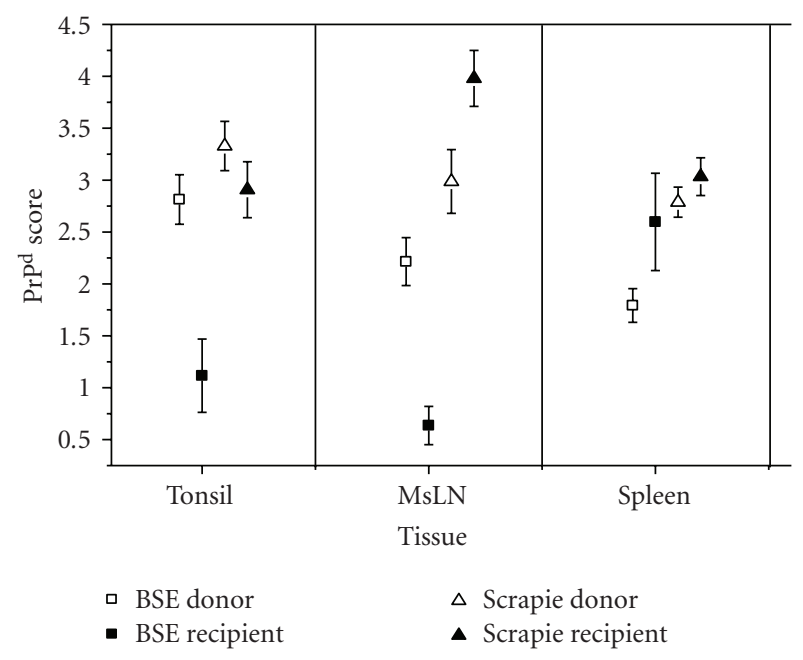

FIgURe 5: Magnitude of $\operatorname{PrP}^{\mathrm{d}}$ accumulation in LRS tissues of sheep as part of the blood transfusion experiment [95]. BSE donor sheep showed the highest levels of $\operatorname{PrP}^{\mathrm{d}}$ accumulation in palatine tonsil and mesenteric lymph node (MsLN) but the lowest in the spleen. In contrast, the spleen in BSE-transfused sheep showed significant higher magnitudes of $\mathrm{PrP}^{\mathrm{d}}$. Graphic representation including scrapie data has been modified from $[96,97]$.

LRS involvement regardless of the involvement or otherwise of neural tissues [115]. In the gut loop experiments described previously [39], in which $\mathrm{PrP}^{\mathrm{d}}$ was detected rapidly in lymphatics, PPs of the intestine became infected at an early disease stage: as no evidence was obtained for the inoculum being transported across the dome to the PPs, the most likely source of scrapie infection of FDCs is thought to be from blood.

\subsection{Evidence That Infectivity in Blood May Establish Brain} Infection. In the brains of BSE-infected sheep, the distribution of $\operatorname{PrP}^{\mathrm{d}}$ was found to be similar irrespective of the route of inoculation being intravascular, intracerebral, or alimentary [63], suggesting common patterns of neuroinvasion and CNS spread. The findings of vascular amyloid $\operatorname{PrP}^{\mathrm{d}}$ deposition in the basement membrane of endothelial cells of the hypothalamus [51] were an early indication that infectivity could reach the brain from the blood. However, such vascular $\mathrm{PrP}^{\mathrm{d}}$ plaques are a relatively rare finding in TSEs [116], which would not justify haematogenous neuroinvasion being a frequent event or having an important role.

It is generally accepted that access of infectious agents to the brain via the blood is hampered by a defensive mechanism: the so-called blood-brain barrier. However, there are specific structures in the brain, the circumventricular organs (CVOs) which, having fenestrated capillaries, are more permissive than other brain areas to the passage of large molecules and provide a two-way communication between CNS and the rest of the body. Recent studies have shown that $\mathrm{PrP}^{\mathrm{d}}$ accumulation in the CVOs of sheep was an early and consistent event that was not affected by the route of challenge or TSE strain, suggesting that
CNS entry of infectivity can occur through these structures [92]. No evidence has been obtained that arrival of $\operatorname{PrP}^{\mathrm{d}}$ in the CVOs is cell-mediated, as white blood cells were not observed in these organs at preclinical or clinical stage of disease; it is therefore possible that TSE agents are present in plasma as cell-free, soluble molecules. This hypothesis would be reinforced by the above-mentioned findings of $\mathrm{PrP}^{\mathrm{d}}$ in kidneys of scrapie-affected sheep $[96,97,112]$, which suggest that $\mathrm{PrP}^{\mathrm{d}}$ arrives in the renal papillary interstitium by filtration or extravasation of soluble molecules. Similarly, CVOs could initially up-take soluble infectivity present in plasma (or in CSF) and act as receptors, supporters, and transporters of infectivity. The variability in severity of $\operatorname{PrP}^{\mathrm{d}}$ accumulation observed between examined CVOs may suggest different participation of these organs in terms of acquiring and amplifying infectivity. Hypothetically, the sensory CVOs may be more susceptible to initial infection, and the secretory CVOs in releasing it to extracranial structures; that is, infectivity present in the pituitary gland may be transported into the adrenal gland.

Once infection is established in the sensory CVOs further spread to neighbouring neural structures through efferent connections could occur (Figure 6). Thus, for example, $\mathrm{PrP}^{\mathrm{d}}$ in the hypothalamic paraventricular nucleus and in the bed nucleus of the stria terminalis could result from spread from the subfornical organ and from the organum vasculosum of the lamina terminalis rather than from the DMNV. The involvement of the DMNV and the area postrema is often simultaneous $[98,115]$ making it difficult to determine if the mechanism of entry of infection at this level of the brain is through the vagus nerve or from the blood, or from both. If the access was from blood through the area postrema, or through CVOs in general, it is possible that neurons of these organs would be infected and would start to accumulate $\mathrm{PrP}^{\mathrm{d}}$ as soon as any circulating infectivity in blood reaches them. However, it might also be possible that neurons of neighbouring structures, such as the DMNV or the hypothalamus, to which CVOs are connected, amplify infectivity or accumulate $\operatorname{PrP}^{\mathrm{d}}$ more rapidly than CVO neurones, resulting in an earlier detection in those structures.

Until recently, the CVOs had received no or very little attention in any human or animal TSE. McBride et al. [22] reported absence of $\mathrm{PrP}^{\mathrm{d}}$ immunodeposits in the area postrema of hamsters experimentally inoculated with scrapie by the oral route but investigations did not address the involvement of other CVOs. Similarly, no CVOs were studied in mule deer with chronic wasting disease, in which the hypothalamus was reported to accumulate $\operatorname{PrP}^{\mathrm{d}}$ before the medulla but after the DMNV [117]. We routinely examine the CVOs in current experiments and have retrospectively examined formalin-fixed brains from earlier studies. So far, we have found $\mathrm{PrP}^{\mathrm{d}}$ deposition in CVOs from clinically affected animals of different species infected with several strains (Figure 7), such as in mice intracerebrally infected with ME7, 87V, 79A, 22A, and 301V strains, and deer [11] and cattle orally infected with cattle BSE, (Sisó et al. unpublished observations) and in goats with natural scrapie [115]. 


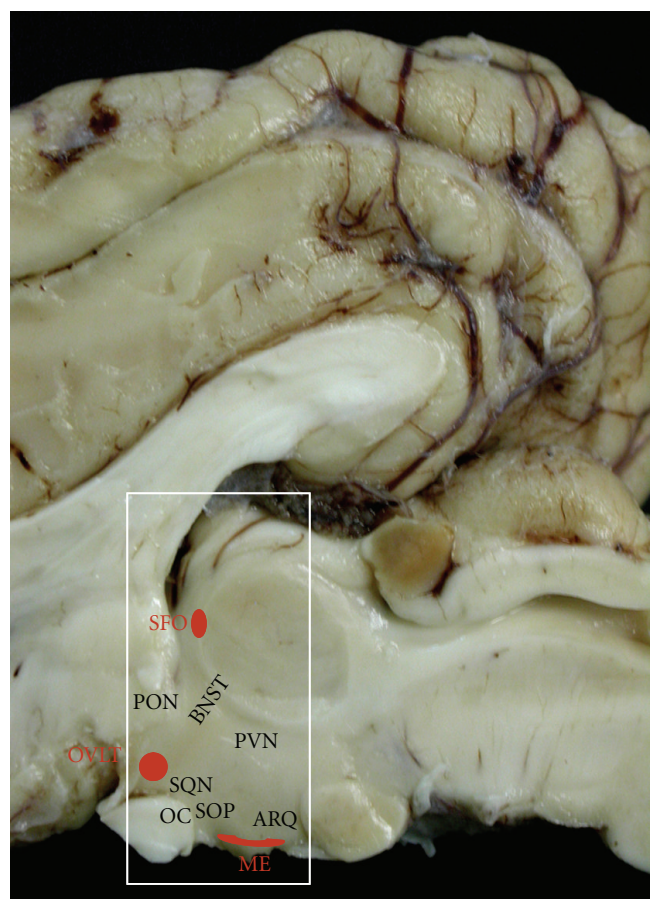

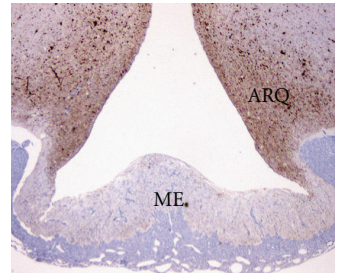

(a)

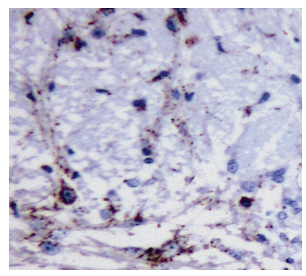

(c)

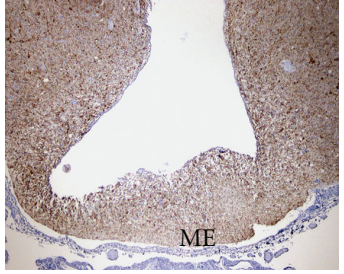

(b)

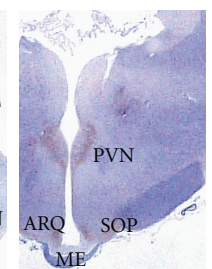

(e)

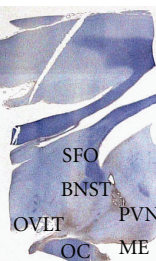

(d)

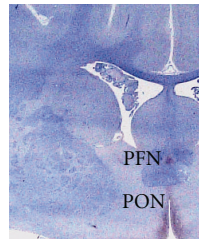

(f)

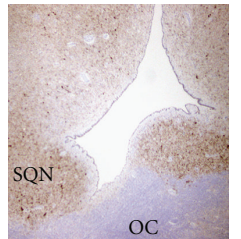

(g)

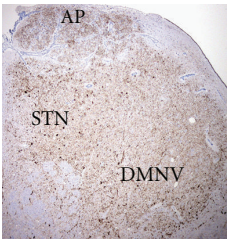

(h)

FIGURE 6: CVO involvement may contribute to the spread of infection into the brain parenchyma. Preclinically affected TSE sheep show mild early $\mathrm{PrP}^{\mathrm{d}}$ accumulation in the median eminence (ME) ( $\left.\mathrm{a} ; \mathrm{x} 4\right)$, or severe deposition in later stages (b; $\mathrm{x} 4$ ). Higher magnification is needed to detect mild $\operatorname{PrP}^{\mathrm{d}}$ accumulation in the ME $(\mathrm{c} ; \mathrm{x} 60)$. In later stages, preclinical sheep do show accumulation of $\operatorname{PrP}^{\mathrm{d}}$ in those brain areas with established connections with the CVOs. A sagittal section of the diencephalon $(\mathrm{d} ; \mathrm{x} 1)$ has been produced from the area compressed in the white rectangle in the macroscopic sagittal view of the brain highlighting some of the neural structures. Thus, the involvement of the ME correlates with $\operatorname{PrP}^{\mathrm{d}}$ accumulation in the arcuate nucleus (ARQ) (a,b,e), and that of the organum vasculosum of the lamina terminalis (OVLT) and the subfornical organ (SFO) correlates with $\mathrm{PrP}^{\mathrm{d}}$ in several nuclei: preoptic (PON) (f, x1), suprachiasmatic (SQN) (g; $\left.\mathrm{x} 4\right)$, supraoptic (SOP) (e, x1), paraventricular (PVN) (d,e), bed nucleus of the stria terminalis (BNST) (d) and perifornical (PFN) (f). Such correlations are difficult in the vagal complex because of the widespread severe $\operatorname{PrP}^{\mathrm{d}}$ accumulation $(\mathrm{h})$.
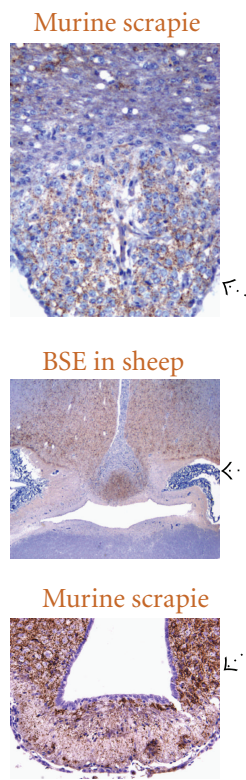
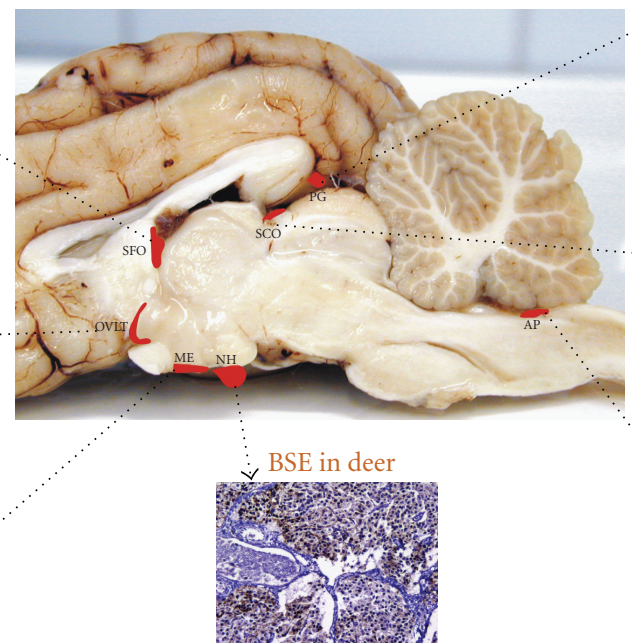

BSE in cattle

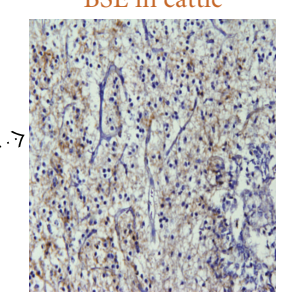

BSE in sheep
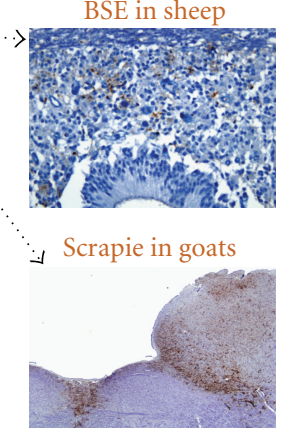

FIGURE 7: PrP $P^{\mathrm{d}}$ accumulation within CVOs in clinically affected animals with different TSE strains. AP, area postrema; PG, pineal gland; ME, median eminence; SCO, subcommisural organ; OVLT, organum vasculosum of lamina terminalis; SFO, subfornical organ; NH, neurophypophysis. 


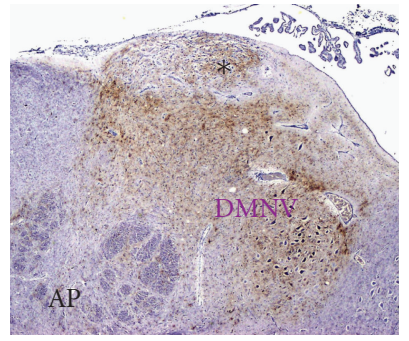

(a)

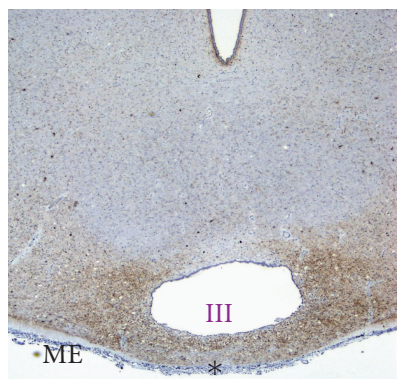

(c)

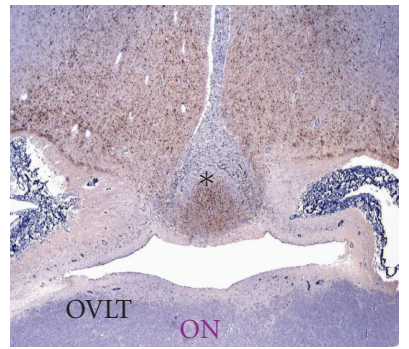

(e)

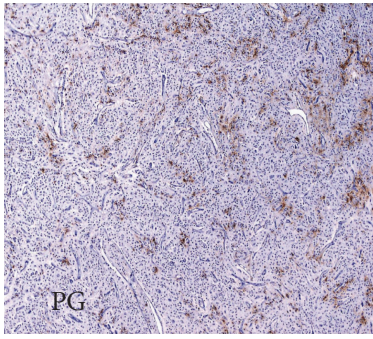

(b)

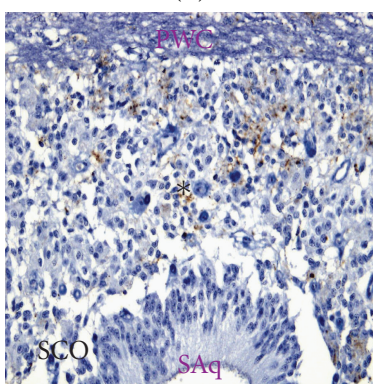

(d)

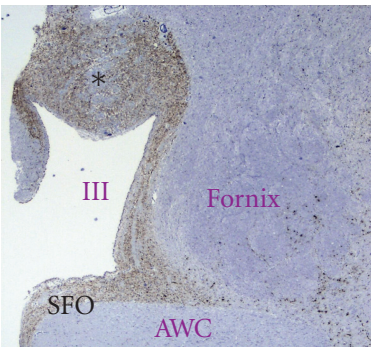

(f)

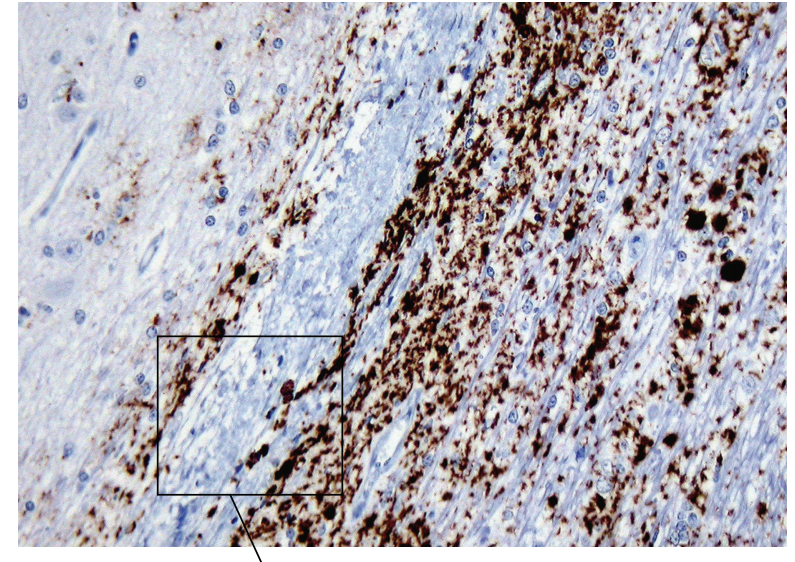

(g)

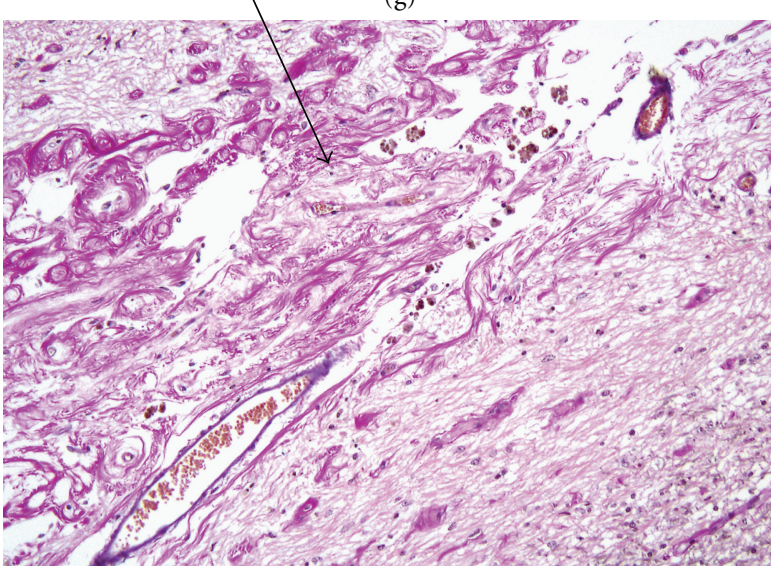

(h)

Figure 8: $\operatorname{Pr}^{\mathrm{d}}$ accumulation in CVOs and in the porencephalic lesion. Sheep CVOs highlighted with an asterix in pictures (a-f) of low magnification showed consistent $\mathrm{PrP}^{\mathrm{d}}$ deposition after intracerebral inoculation with BSE. Note that the porencephalic lesion which is surrounded by $\operatorname{PrP}^{\mathrm{d}}$ accumulations ( $\mathrm{g}$; $\mathrm{x} 10$ ) has abundant proliferation of newly formed vessels as revealed by a Van-Gieson staining (h; x20). CVOs: AP, area postrema; PG, pineal gland; ME, median eminence; SCO, subcommisural organ; OVLT, organum vasculosum of the lamina terminalis; SFO, subfornical organ. Brain structures: DMNV, dorsal nucleus of the vagus nerve; IV, fourth ventricle; Saq, Silvios' acqueduct; ON, optic chiasm; III, third ventricle; AWC, anterior white commisure. The figure is modified from (Sisó et al. [98]).

A further support for a blood-borne neuroinvasion pathway was provided by the study of the topographical distribution of $\operatorname{PrP}^{\mathrm{d}}$ in the brain of 27 sheep that had been intracerebrally challenged with BSE and presented porencephalic lesions resulting from the traumatic injury [98]. The key findings (Figure 8) were as follows: (i) same PrPd topography, involving bilaterally the DMNV and the hypothalamus, as for infections by other routes; (ii) involvement of CVOs; (iii) focal accumulation of $\operatorname{PrP}^{\mathrm{d}}$ at the porencephalic lesions, but extending locally to neighbouring ipsilateral cerebrocortical areas in some cases; and (iv) absence of $\operatorname{PrP}^{\mathrm{d}}$ in such lesions in cases that did not accumulate $\operatorname{PrP}^{\mathrm{d}}$ anywhere else in the brain. It was therefore suggested that, rather than a local replication of the infectious agent at the site of injection, the inoculum would be completely reabsorbed into the CSF and recirculated in the blood gaining access back to the brain through the CVOs and through the porencephalic lesions, where fenestrated neocapillaries were also abundant as part of the repair tissue process.
The haematogenous route, therefore, can represent a parallel or alternative pathway of neuroinvasion to ascending infection via the ENS and autonomic nervous system by accessing the CVOs and encephalic lesions of traumatic or vascular origin. Figure 9 represents schematically the possible pathways of neuroinvasion to be considered in TSEs.

\section{Conclusions}

The most widely accepted neuroinvasion mechanism in prion diseases is thought to involve amplification of infectivity within lymphoid tissues and subsequent retrograde spread of infection along autonomic nervous system nerves until it reaches the brain. However, the peripheral pathogenesis of prion diseases can vary depending on several factors. In most TSE cases, infection of the lymphoid system appears to facilitate neuroinvasion, increasing attack rates and shortening incubation periods, although in some scrapie cases and in most or all of natural BSE cases and in SCJD, the lymphoid system does not seem to be involved. In view 


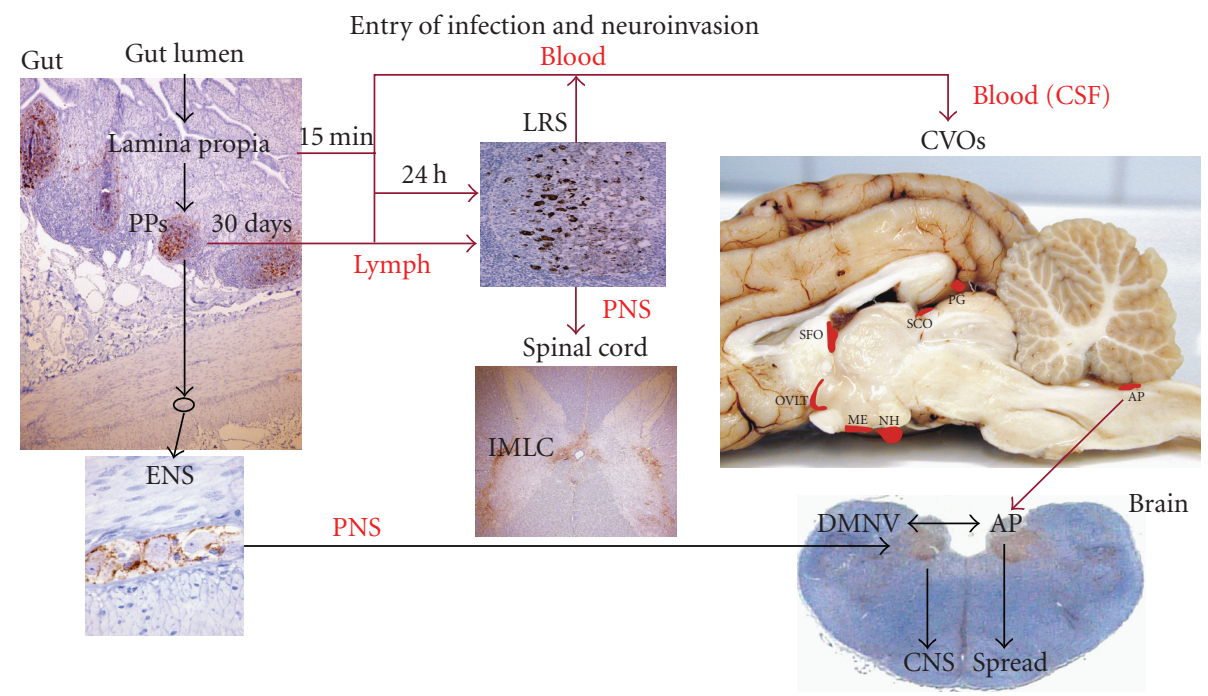

FIGURE 9: Schematic view of the neuroinvasion process involving the roles of the blood and the CVOs. For abbreviations see text and Figure 7 legend.

of the fact that, regardless of the route of infection and other factors that affect the peripheral pathogenesis (agent, PRNP genotype, etc.), the initial accumulation of $\operatorname{PrP}^{\mathrm{d}}$ in the brain and its spread appears to follow the same pattern, it is unlikely that neuroinvasion occurs solely by a mechanism involving retrograde transport of infectivity along peripheral nerves, at least those of the ENS/PNS axis, as the prevailing view suggests.

Alternatively, the observation that $\operatorname{PrP}^{\mathrm{d}}$ accumulates in peripheral organs, such as the kidney or the mammary gland, as does in the LRS tissues themselves, clearly shows a vascular dispersion of infectivity, which is consistent with an haematogenous route of neuroinvasion. Additional support for this alternative pathway derives from the early and systematic detection of $\mathrm{PrP}^{\mathrm{d}}$ in the CVOs which, lacking a blood-brain barrier, could act as portals of entry of infection.

Whether the haematogenous neuroinvasion pathway is coincidental with a neural pathway, and the relative importance of them for different TSEs, remains to be determined.

\section{References}

[1] H. Fraser, "Neuronal spread of scrapie agent and targeting of lesions within the retino-tectal pathway," Nature, vol. 295, no. 5845, pp. 149-150, 1982.

[2] J. R. Scott and H. Fraser, "Transport and targeting of scrapie infectivity and pathology in the optic nerve projections following intraocular infection," Progress in Clinical and Biological Research, vol. 317, pp. 645-652, 1989.

[3] J. C. Bartz, A. E. Kincaid, and R. A. Bessen, "Rapid prion neuroinvasion following tongue infection," Journal of Virology, vol. 77, no. 1, pp. 583-591, 2003.

[4] A. E. Kincaid and J. C. Bartz, "The nasal cavity is a route for prion infection in hamsters," Journal of Virology, vol. 81, no. 9, pp. 4482-4491, 2007.
[5] M. Sbriccoli, F. Cardone, A. Valanzano, et al., "Neuroinvasion of the $263 \mathrm{~K}$ scrapie strain after intranasal administration occurs through olfactory-unrelated pathways," Acta Neuropathologica, vol. 117, no. 2, pp. 175-184, 2009.

[6] R. A. Bessen, S. Martinka, J. Kelly, and D. Gonzalez, "Role of the lymphoreticular system in prion neuroinvasion from the oral and nasal mucosa," Journal of Virology, vol. 83, no. 13, pp. 6435-6445, 2009.

[7] R. H. Kimberlin, H. J. Field, and C. A. Walker, "Pathogenesis of mouse scrapie: evidence for spread of infection from central to peripheral nervous system," Journal of General Virology, vol. 64, no. 3, pp. 713-716, 1983.

[8] J. C. Bartz, A. E. Kincaid, and R. A. Bessen, "Retrograde transport of transmissible mink encephalopathy within descending motor tracts," Journal of Virology, vol. 76, no. 11, pp. 5759-5768, 2002.

[9] M. L. Cook and J. G. Stevens, "Pathogenesis of herpetic neuritis and ganglionitis in mice: evidence for intra-axonal transport of infection," Infection and Immunity, vol. 7, no. 2, pp. 272-288, 1973.

[10] P. Kucera, M. Dolivo, P. Coulon, and A. Flamand, "Pathways of the early propagation of virulent and avirulent rabies strains from the eye to the brain," Journal of Virology, vol. 55, no. 1, pp. 158-162, 1985.

[11] S. Martin, M. Jeffrey, L. González, et al., "Immunohistochemical and biochemical characteristics of BSE and CWD in experimentally infected European red deer (Cervus elaphus elaphus)," BMC Veterinary Research, vol. 5, article 26, 2009.

[12] C. M. Eklund, R. C. Kennedy, and W. J. Hadlow, "Pathogenesis of scrapie virus infection in the mouse," Journal of Infectious Diseases, vol. 117, no. 1, pp. 15-22, 1967.

[13] R. H. Kimberlin and C. A. Walker, "Pathogenesis of scrapie in mice after intragastric infection," Virus Research, vol. 12, no. 3, pp. 213-220, 1989.

[14] R. H. Kimberlin and C. A. Walker, "Pathogenesis of experimental scrapie," in Novel Infectious Agents and the Central Nervous System, vol. 135 of Ciba Foundation Symposium, pp. 37-62, Wiley, Chichester, UK, 1988. 
[15] R. H. Kimberlin and C. A. Walker, "The role of the spleen in the neuroinvasion of scrapie in mice," Virus Research, vol. 12, no. 3, pp. 201-212, 1989.

[16] R. H. Kimberlin and C. A. Walker, "Pathogenesis of mouse scrapie: effect of route of inoculation on infectivity titres and dose-response curves," Journal of Comparative Pathology, vol. 88, no. 1, pp. 39-47, 1978.

[17] R. H. Kimberlin and C. A. Walker, "Pathogenesis of mouse scrapie: patterns of agent replication in different parts of the CNS following intraperitoneal infection," Journal of the Royal Society of Medicine, vol. 75, no. 8, pp. 618-624, 1982.

[18] M. C. Clarke and R. H. Kimberlin, "Pathogenesis of mouse scrapie: distribution of agent in the pulp and stroma of infected spleens," Veterinary Microbiology, vol. 9, no. 3, pp. 215-225, 1984.

[19] N. Buyukmihci, F. Goehring-Harmon, and R. F. Marsh, "Asymmetry of retinal lesions in experimental scrapie after intracerebral inoculation of hamsters," Experimental Neurology, vol. 87, no. 1, pp. 172-176, 1985.

[20] E. Baldauf, M. Beekes, and H. Diringer, "Evidence for an alternative direct route of access for the scrapie agent to the brain bypassing the spinal cord," Journal of General Virology, vol. 78, no. 5, pp. 1187-1197, 1997.

[21] M. Beekes, E. Baldauf, and H. Diringer, "Sequential appearance and accumulation of pathognomonic markers in the central nervous system of hamsters orally infected with scrapie," Journal of General Virology, vol. 77, no. 8, pp. 19251934, 1996.

[22] P. A. McBride, W. J. Schulz-Schaeffer, M. Donaldson, et al., "Early spread of scrapie from the gastrointestinal tract to the central nervous system involves autonomic fibers of the splanchnic and vagus nerves," Journal of Virology, vol. 75, no. 19, pp. 9320-9327, 2001.

[23] M. Beekes, P. A. McBride, and E. Baldauf, "Cerebral targeting indicates vagal spread of infection in hamsters fed with scrapie," Journal of General Virology, vol. 79, no. 3, pp. 601607, 1998.

[24] P. A. McBride and M. Beekes, "Pathological PrP is abundant in sympathetic and sensory ganglia of hamsters fed with scrapie," Neuroscience Letters, vol. 265, no. 2, pp. 135-138, 1999.

[25] M. Beekes and P. A. McBride, "Early accumulation of pathological PrP in the enteric nervous system and gutassociated lymphoid tissue of hamsters orally infected with scrapie," Neuroscience Letters, vol. 278, no. 3, pp. 181-184, 2000.

[26] N. A. Mabbott and M. E. Bruce, "The immunology of TSE diseases," Journal of General Virology, vol. 82, pp. 2307-2318, 2001.

[27] H. Diringer, "Sustained viremia in experimental hamster scrapie. Brief report," Archives of Virology, vol. 82, no. 1-2, pp. 105-109, 1984.

[28] R. H. Kimberlin and C. A. Walker, "Pathogenesis of scrapie (strain 263k) in hamsters infected intracerebrally, intraperitoneally or intraocularly," Journal of General Virology, vol. 67, no. 2, pp. 255-263, 1986.

[29] Y. Kuroda, C. J. Gibbs Jr., H. L. Amyx, and D. C. Gajdusek, "Creutzfeldt-Jakob disease in mice: persistent viremia and preferential replication of virus in low-density lymphocytes," Infection and Immunity, vol. 41, no. 1, pp. 154-161, 1983.

[30] M. A. Klein, R. Frigg, E. Flechsig, et al., "A crucial role for B cells in neuroinvasive scraple," Nature, vol. 390, no. 6661, pp. 687-690, 1997.
[31] M. A. Klein, R. Frigg, A. J. Raeber, et al., "PrP expression in B lymphocytes is not required for prion neuroinvasion," Nature Medicine, vol. 4, no. 12, pp. 1429-1433, 1998.

[32] K. L. Brown, K. Stewart, D. L. Ritchie, et al., "Scrapie replication in lymphoid tissues depends on prion proteinexpressing follicular dendritic cells," Nature Medicine, vol. 5, no. 11, pp. 1308-1312, 1999.

[33] N. A. Mabbott, A. Williams, C. F. Farquhar, M. Pasparakis, G. Kollias, and M. E. Bruce, "Tumor necrosis factor alphadeficient, but not interleukin-6-deficient, mice resist peripheral infection with scrapie," Journal of Virology, vol. 74, no. 7, pp. 3338-3344, 2000.

[34] V. Beringue, M. Demoy, C. I. Lasmézas, et al., "Role of spleen macrophages in the clearance of scrapie agent early in pathogenesis," Journal of Pathology, vol. 190, no. 4, pp. 495502, 2000.

[35] G. A. Davies, A. R. Bryant, J. D. Reynolds, F. R. Jirik, and K. A. Sharkey, "Prion diseases and gastrointestinal tract," Canadian Journal of Gastroenterology, vol. 20, no. 1, pp. 18-24, 2006.

[36] G. Dorban, V. Defaweux, C. Demonceau, et al., "Interaction between dendritic cells and nerve fibres in lymphoid organs after oral scrapie exposure," Virchows Archiv, vol. 451, no. 6, pp. 1057-1065, 2007.

[37] F.-P. Huang, C. F. Farquhar, N. A. Mabbott, M. E. Bruce, and G. G. MacPherson, "Migrating intestinal dendritic cells transport PrPSc from the gut," Journal of General Virology, vol. 83, no. 1, pp. 267-271, 2002.

[38] M. Jeffrey, L. González, A. Chong, et al., "Ovine infection with the agents of scrapie (CH1641 isolate) and bovine spongiform encephalopathy: immunochemical similarities can be resolved by immunohistochemistry," Journal of Comparative Pathology, vol. 134, no. 1, pp. 17-29, 2006.

[39] M. Jeffrey, L. González, A. Espenes, et al., "Transportation of prion protein across the intestinal mucosa of scrapiesusceptible and scrapie-resistant sheep," Journal of Pathology, vol. 209, no. 1, pp. 4-14, 2006.

[40] M. J. Ford, L. J. Burton, R. J. Morris, and S. M. Hall, "Selective expression of prion protein in peripheral tissues of the adult mouse," Neuroscience, vol. 113, no. 1, pp. 177-192, 2002.

[41] A. Aguzzi, F. L. Heppner, M. Heikenwalder, et al., "Immune system and peripheral nerves in propagation of prions to CNS," British Medical Bulletin, vol. 66, pp. 141-159, 2003.

[42] T. Blattler, S. Brandner, A. J. Raeber, et al., "PrP-expressing tissue required for transfer of scrapie infectivity from spleen to brain," Nature, vol. 389, no. 6646, pp. 69-73, 1997.

[43] M. Glatzel, F. L. Heppner, K. M. Albers, and A. Aguzzi, "Sympathetic innervation of lymphoreticular organs is rate limiting for prion neuroinvasion," Neuron, vol. 31, no. 1, pp. 25-34, 2001.

[44] S. L. Carlson, K. M. Albers, D. J. Belting, M. Parish, J. M. Conner, and B. M. Davis, "NGF modulates sympathetic innervation of lymphoid tissues," Journal of Neuroscience, vol. 15, no. 9, pp. 5892-5899, 1995.

[45] W. J. Hadlow, R. C. Kennedy, R. E. Race, and C. M. Eklund, "Virologic and neurohistologic findings in dairy goats affected with natural scrapie," Veterinary Pathology, vol. 17, pp. 187-199, 1980.

[46] W. J. Hadlow, R. C. Kennedy, and R. E. Race, "Natural infection of Suffolk sheep with scrapie virus," Journal of Infectious Diseases, vol. 146, pp. 657-664, 1982.

[47] M. H. Groschup, F. Weiland, O. C. Straub, and E. Pfaff, "Detection of scrapie agent in the peripheral nervous system of a diseased sheep," Neurobiology of Disease, vol. 3, no. 3, pp. 191-195, 1996. 
[48] M. H. Groschup, M. Beekes, P. A. McBride, M. Hardt, J. A. Hainfellner, and H. Budka, "Deposition of disease-associated prion protein involves the peripheral nervous system in experimental scrapie," Acta Neuropathologica, vol. 98, no. 5, pp. 453-457, 1999.

[49] O. Andréoletti, P. Berthon, D. Marc, et al., "Early accumulation of $\operatorname{PrP}(\mathrm{Sc})$ in gut-associated lymphoid and nervous tissues of susceptible sheep from a Romanov flock with natural scrapie," Journal of General Virology, vol. 81, no. 12, pp. 3115-3126, 2000.

[50] L. J. M. van Keulen, B. E. C. Schreuder, M. E. W. Vromans, J. P. M. Langeveld, and M. A. Smits, "Scrapie-associated prion protein in the gastrointestinal tract of sheep with natural scrapie," Journal of Comparative Pathology, vol. 121, no. 1, pp. 55-63, 1999.

[51] L. J. van Keulen, B. E. Schreuder, M. E. Vromans, J. P. Langeveld, and M. A. Smits, "Pathogenesis of natural scrapie in sheep," Archives of Virology Supplementum, no. 16, pp. 57$71,2000$.

[52] M. Jeffrey, S. Martin, L. González, et al., "Cell-associated variants of disease-specific prion protein immunolabelling are found in different sources of sheep transmissible spongiform encephalopathy," Journal of General Virology, vol. 84, pp. 1033-1045, 2003.

[53] L. J. M. van Keulen, M. E. W. Vromans, and F. G. van Zijderveld, "Early and late pathogenesis of natural scrapie infection in sheep," Acta Pathologica, Microbiologica et Immunologica Scandinavica, vol. 110, no. 1, pp. 23-32, 2002.

[54] M. Jeffrey, S. Martin, J. R. Thomson, W. S. Dingwall, I. Begara-McGorum, and L. González, "Onset and distribution of tissue PrP accumulation in scrapie-affected Suffolk sheep as demonstrated by sequential necropsies and tonsillar biopsies," Journal of Comparative Pathology, vol. 125, no. 1, pp. 48-57, 2001.

[55] M. Jeffrey, S. Ryder, S. Martin, et al., "Oral inoculation of sheep with the agent of bovine spongiform encephalopathy (BSE). 1. Onset and distribution of disease-specific PrP accumulation in brain and viscera," Journal of Comparative Pathology, vol. 124, no. 4, pp. 280-289, 2001.

[56] G. McGovern and M. Jeffrey, "Scrapie-specific pathology of sheep lymphoid tissues," PLoS One, vol. 2, no. 12, article e1304, 2007.

[57] R. Heggebø, C. McL. Press, G. Gunnes, et al., "Distribution of prion protein in the ileal Peyer's patch of scrapie-free lambs and lambs naturally and experimentally exposed to the scrapie agent," Journal of General Virology, vol. 81, no. 9, pp. 2327-2337, 2000.

[58] C. Ersdal, M. J. Ulvund, S. L. Benestad, and M. A. Tranulis, "Accumulation of pathogenic prion protein (PrPSc) in nervous and lymphoid tissues of sheep with subclinical scrapie," Vet Pathol, vol. 40, no. 2, pp. 164-174, 2003.

[59] R. Heggebø, L. González, C. McL. Press, G. Gunnes, A. Espenes, and M. Jeffrey, "Disease-associated $\operatorname{PrP}$ in the enteric nervous system of scrapie-affected Suffolk sheep," Journal of General Virology, vol. 84, no. 5, pp. 1327-1338, 2003.

[60] L. J. M. van Keulen, M. E. W. Vromans, C. H. Dolstra, A. Bossers, and F. G. van Zijderveld, "Pathogenesis of bovine spongiform encephalopathy in sheep," Archives of Virology, vol. 153, no. 3, pp. 445-453, 2008.

[61] R. Heggebø, C. McL. Press, G. Gunnes, L. González, and M. Jeffrey, "Distribution and accumulation of PrP in gutassociated and peripheral lymphoid tissue of scrapie-affected
Suffolk sheep," Journal of General Virology, vol. 83, no. 2, pp. 479-489, 2002.

[62] S. J. Bellworthy, S. A. C. Hawkins, R. B. Green, et al., "Tissue distribution of bovine spongiform encephalopathy infectivity in Romney sheep up to the onset of clinical disease after oral challenge," Veterinary Record, vol. 156, no. 7, pp. 197-202, 2005.

[63] L. González, S. Martin, F. E. Houston, et al., "Phenotype of disease-associated PrP accumulation in the brain of bovine spongiform encephalopathy experimentally infected sheep," Journal of General Virology, vol. 86, no. 3, pp. 827-838, 2005.

[64] F. Houston, W. Goldmann, A. Chong, et al., "Prion diseases: BSE in sheep bred for resistance to infection," Nature, vol. 423, no. 6939, p. 498, 2003.

[65] S. Martin, L. González, A. Chong, F. E. Houston, N. Hunter, and M. Jeffrey, "Immunohistochemical characteristics of disease-associated PrP are not altered by host genotype or route of inoculation following infection of sheep with bovine spongiform encephalopathy," Journal of General Virology, vol. 86, no. 3, pp. 839-848, 2005.

[66] L. A. Terry, S. Marsh, S. J. Ryder, S. A. C. Hawkins, G. A. H. Wells, and Y. I. Spencer, "Detection of disease-specific Prp in the distal ileum of cattle exposed orally to the agent of bovine spongiform encephalopathy," Veterinary Record, vol. 152, no. 13, pp. 387-392, 2003.

[67] A. Buschmann and M. H. Groschup, "Highly bovine spongiform encephalopathy-sensitive transgenic mice confirm the essential restriction of infectivity to the nervous system in clinically diseased cattle," Journal of Infectious Diseases, vol. 192, no. 5, pp. 934-942, 2005.

[68] G. A. Wells, M. Dawson, S. A. Hawkins, et al., "Infectivity in the ileum of cattle challenged orally with bovine spongiform encephalopathy," Veterinary Record, vol. 135, no. 2, pp. 4041, 1994.

[69] G. A. H. Wells, S. A. C. Hawkins, R. B. Green, et al., "Preliminary observations on the pathogenesis of experimental bovine spongiform encephalopathy (BSE): an update," Veterinary Record, vol. 142, no. 5, pp. 103-106, 1998.

[70] G. A. H. Wells, J. Spiropoulos, S. A. C. Hawkins, and S. J. Ryder, "Pathogenesis of experimental bovine spongiform encephalopathy: preclinical infectivity in tonsil and observations on the distribution of lingual tonsil in slaughtered cattle," Veterinary Record, vol. 156, no. 13, pp. 401-407, 2005.

[71] C. Hoffmann, U. Ziegler, A. Buschmann, et al., "Prions spread via the autonomic nervous system from the gut to the central nervous system in cattle incubating bovine spongiform encephalopathy," Journal of General Virology, vol. 88, no. 3, pp. 1048-1055, 2007.

[72] E. S. Williams, "Chronic wasting disease," Veterinary Pathology, vol. 42, no. 5, pp. 530-549, 2005.

[73] C. J. Sigurdson, "A prion disease of cervids: chronic wasting disease," Veterinary Research, vol. 39, no. 4, article 41, 2008.

[74] C. J. Sigurdson, T. R. Spraker, M. W. Miller, B. Oesch, and E. A. Hoover, "PrPCWD in the myenteric plexus, vagosympathetic trunk and endocrine glands of deer with chronic wasting disease," Journal of General Virology, vol. 82, no. 10, pp. 2327-2334, 2001.

[75] R. A. Bessen and R. F. Marsh, "Identification of two biologically distinct strains of transmissible mink encephalopathy in hamsters," Journal of General Virology, vol. 73, no. 2, pp. 329-334, 1992. 
[76] J. C. Bartz, C. DeJoia, T. Tucker, A. E. Kincaid, and R. A. Bessen, "Extraneural prion neuroinvasion without lymphoreticular system infection," Journal of Virology, vol. 79, no. 18, pp. 11858-11863, 2005.

[77] A. F. Hill, R. J. Butterworth, S. Joiner, et al., "Investigation of variant Creutzfeldt-Jakob disease and other human prion diseases with tonsil biopsy samples," The Lancet, vol. 353, no. 9148, pp. 183-189, 1999.

[78] J. A. Hainfellner and H. Budka, "Disease associated prion protein may deposit in the peripheral nervous system in human transmissible spongiform encephalopathies," Acta Neuropathologica, vol. 98, no. 5, pp. 458-460, 1999.

[79] M. Glatzel, E. Abela, M. Maissen, and A. Aguzzi, "Extraneural pathologic prion protein in sporadic Creutzfeldt-Jakob disease," New England Journal of Medicine, vol. 349, no. 19, pp. 1812-1820, 2003.

[80] G. McGovern, S. Martin, L. González, J. Witz, and M. Jeffrey, "Frequency and distribution of nerves in scrapie-affected and unaffected peyer's patches and lymph nodes," Veterinary Pathology, vol. 46, no. 2, pp. 233-240, 2009.

[81] L. González, M. P. Dagleish, S. Martin, et al., "Ante-mortem diagnosis of preclinical sheep scrapie by immunohistochemical examination of rectal biopsy samples," Veterinary Record, vol. 162, no. 13, pp. 397-403, 2008.

[82] L. J. M. van Keulen, B. E. C. Schreuder, R. H. Meloen, G. Mooij-Harkes, M. E. W. Vromans, and J. P. M. Langeveld, "Immunohistochemical detection of prion protein in lymphoid tissues of sheep with natural scrapie," Journal of Clinical Microbiology, vol. 34, no. 5, pp. 1228-1231, 1996.

[83] M. Jeffrey, I. Begara-McGorum, S. Clark, et al., "Occurrence and distribution of infection-specific $\mathrm{PrP}$ in tissues of clinical scrapie cases and cull sheep from scrapie-affected farms in Shetland," Journal of Comparative Pathology, vol. 127, no. 4, pp. 264-273, 2002.

[84] L. González, S. Martin, S. Sisó, et al., "High prevalence of scrapie in a dairy goat herd: tissue distribution of diseaseassociated PrP and effect of PRNP genotype and age," Veterinary Research, vol. 40, no. 6, article 65, 2009.

[85] M. W. Head, D. Ritchie, N. Smith, et al., "Peripheral tissue involvement in sporadic, iatrogenic, and variant CreutzfeldtJakob disease: an immunohistochemical, quantitative, and biochemical study," American Journal of Pathology, vol. 164, no. 1, pp. 143-153, 2004.

[86] S. L. Benestad, J.-N. Arsac, W. Goldmann, and M. Nöremark, "Atypical/Nor98 scrapie: properties of the agent, genetics, and epidemiology," Veterinary Research, vol. 39, no. 4, article 19, 2008.

[87] D. L. Felten, S. Y. Felten, and S. L. Carlson, "Noradrenergic and peptidergic innervation of lymphoid tissue," Journal of Immunology, vol. 135, supplement 2, pp. 755s-765s, 1985.

[88] D. L. Felten and S. Y. Felten, "Sympathetic noradrenergic innervation of immune organs," Brain Behavior and Immunity, vol. 2, no. 4, pp. 293-300, 1988.

[89] A. Bencsik, S. Lezmi, and T. Baron, "Autonomous nervous system innervation of lymphoid territories in spleen: a possible involvement of nonadrenergic neurons for prion neuroinvasion in natural scrapie," Journal of Neurovirology, vol. 7, no. 5, pp. 447-453, 2001.

[90] A. Bencsik, S. Lezmi, G. Hunsmann, and T. Baron, "Close vicinity of $\mathrm{PrP}$ expressing cells (FDC) with noradrenergic fibers in healthy sheep spleen," Developmental Immunology, vol. 8, no. 3-4, pp. 235-241, 2001.
[91] D. L. Felten, S. Y. Felten, D. L. Bellinger, et al., "Noradrenergic sympathetic neural interactions with the immune system: structure and function," Immunological Reviews, no. 100, pp. 225-260, 1987.

[92] S. Sisó, M. Jeffrey, and L. González, "Neuroinvasion in sheep transmissible spongiform encephalopathies: the role of the haematogenous route," Neuropathology and Applied Neurobiology, vol. 35, no. 3, pp. 232-246, 2009.

[93] M. W. Head, H. M. Yull, D. L. Ritchie, M. T. Bishop, and J. W. Ironside, "Pathological investigation of the first blood donor and recipient pair linked by transfusion-associated variant Creutzfeldt-Jakob disease transmission," Neuropathology and Applied Neurobiology, vol. 35, no. 4, pp. 433-436, 2009.

[94] G. C. Millson, R. H. Kimberlin, E. J. Manning, and S. C. Collis, "Early distribution of radioactive liposomes and scrapie infectivity in mouse tissues following administration by different routes," Veterinary Microbiology, vol. 4, no. 2, pp. 89-99, 1979.

[95] F. Houston, S. McCutcheon, W. Goldmann, et al., "Prion diseases are efficiently transmitted by blood transfusion in sheep," Blood, vol. 112, no. 12, pp. 4739-4745, 2008.

[96] S. Sisó, L. González, F. Houston, N. Hunter, S. Martin, and M. Jeffrey, "The neuropathologic phenotype of experimental ovine BSE is maintained after blood transfusion," Blood, vol. 108, no. 2, pp. 745-748, 2006.

[97] S. Sisó, L. González, M. Jeffrey, S. Martin, F. Chianini, and P. Steele, "Prion protein in kidneys of scrapie-infected sheep," Veterinary Record, vol. 159, no. 10, pp. 327-328, 2006.

[98] S. Sisó, M. Jeffrey, S. Martin, F. Houston, N. Hunter, and L. González, "Pathogenetical significance of porencephalic lesions associated with intracerebral inoculation of sheep with the bovine spongiform encephalopathy (BSE) agent," Neuropathology and Applied Neurobiology, vol. 35, no. 3, pp. 247-258, 2009.

[99] F. Houston, J. D. Foster, A. Chong, N. Hunter, and C. J. Bostock, "Transmission of BSE by blood transfusion in sheep," The Lancet, vol. 356, no. 9234, pp. 999-1000, 2000.

[100] N. Hunter, J. Foster, A. Chong, et al., "Transmission of prion diseases by blood transfusion," Journal of General Virology, vol. 83, no. 11, pp. 2897-2905, 2002.

[101] S. Sisó, M. Jeffrey, F. Houston, N. Hunter, S. Martin, and L. González, "Pathological phenotype of sheep scrapie after blood transfusion," Journal of Comparative Pathology, vol. 142, no. 1, pp. 27-35, 2010.

[102] C. K. Mathiason, J. G. Powers, S. J. Dahmes, et al., "Infectious prions in the saliva and blood of deer with chronic wasting disease," Science, vol. 314, no. 5796, pp. 133-136, 2006.

[103] C. A. Llewelyn, P. E. Hewitt, R. S. G. Knight, et al., "Possible transmission of variant Creutzfeldt-Jakob disease by blood transfusion," The Lancet, vol. 363, no. 9407, pp. 417-421, 2004.

[104] A. H. Peden, M. W. Head, D. L. Ritchie, P. J. E. Bell, and P. J. W. Ironside, "Preclinical vCJD after blood transfusion in a PRNP codon 129 heterozygous patient," The Lancet, vol. 364, no. 9433, pp. 527-529, 2004.

[105] S. J. Wroe, S. Pal, D. Siddique, et al., "Clinical presentation and pre-mortem diagnosis of variant Creutzfeldt-Jakob disease associated with blood transfusion: a case report," The Lancet, vol. 368, no. 9552, pp. 2061-2067, 2006.

[106] HPA Press Statement, "4th case of variant CJD infection associated with blood transfusion," Health Protection Agency, 2007, http://www.hpa.org.uk/hpa/news/articles/press_releases/2007/070118_vCJD.htm. 
[107] HPA Press Statement, "vCJD abnormal prion protein found in a patient with haemophilia at post mortem," Health Protection Agency, 2009, http://www.hpa.org.uk/webw/ HPAweb\&HPAwebStandard/HPAweb_C/1234859690542?p= 1231252394302

[108] P. Saá, J. Castilla, and C. Soto, "Presymptomatic detection of prions in blood," Science, vol. 313, no. 5783, pp. 92-94, 2006.

[109] O. Andréoletti, C. Lacroux, A. Chabert, et al., "PrPSc accumulation in placentas of ewes exposed to natural scrapie: influence of foetal PrP genotype and effect on ewe-to-lamb transmission," Journal of General Virology, vol. 83, no. 10, pp. 2607-2616, 2002.

[110] C. Ligios, C. J. Sigurdson, C. Santucciu, et al., "PrPSc in mammary glands of sheep affected by scrapie and mastitis," Nature Medicine, vol. 11, no. 11, pp. 1137-1138, 2005.

[111] M. Vascellari, R. Nonno, F. Mutinelli, et al., "PrPSc in salivary glands of scrapie-affected sheep," Journal of Virology, vol. 81, no. 9, pp. 4872-4876, 2007.

[112] S. Sisó, M. Jeffrey, P. Steele, et al., "Occurrence and cellular localization of PrPd in kidneys of scrapie-affected sheep in the absence of inflammation," Journal of Pathology, vol. 215, no. 2, pp. 126-134, 2008.

[113] C. Lacroux, S. Simon, S. L. Benestad, et al., "Prions in milk from ewes incubating natural scrapie," PLoS Pathogens, vol. 4, no. 12, article e1000238, 2008.

[114] T. Konold, S. J. O. Moore, S. J. Bellworthy, and H. A. Simmons, "Evidence of scrapie transmission via milk," BMC Veterinary Research, vol. 4, article 14, 2008.

[115] L. González, S. Martin, S. A. Hawkins, et al., "Pathogenesis of natural goat scrapie: modulation by host PRNP genotype and effect of co-existent conditions," Veterinary Research, vol. 41, no. 4, p. 48, 2010.

[116] L. González, S. Martin, I. Begara-McGorum, et al., "Effects of agent strain and host genotype on $\mathrm{PrP}$ accumulation in the brain of sheep naturally and experimentally affected with scrapie," Journal of Comparative Pathology, vol. 126, no. 1, pp. 17-29, 2002.

[117] T. R. Spraker, R. R. Zink, B. A. Cummings, C. J. Sigurdson, M. W. Miller, and K. I. O'Rourke, "Distribution of proteaseresistant prion protein and spongiform encephalopathy in free-ranging mule deer (Odocoileus hemionus) with chronic wasting disease," Veterinary Pathology, vol. 39, no. 5, pp. 546$556,2002$. 


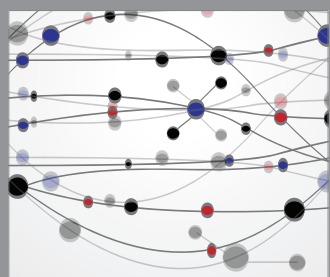

The Scientific World Journal
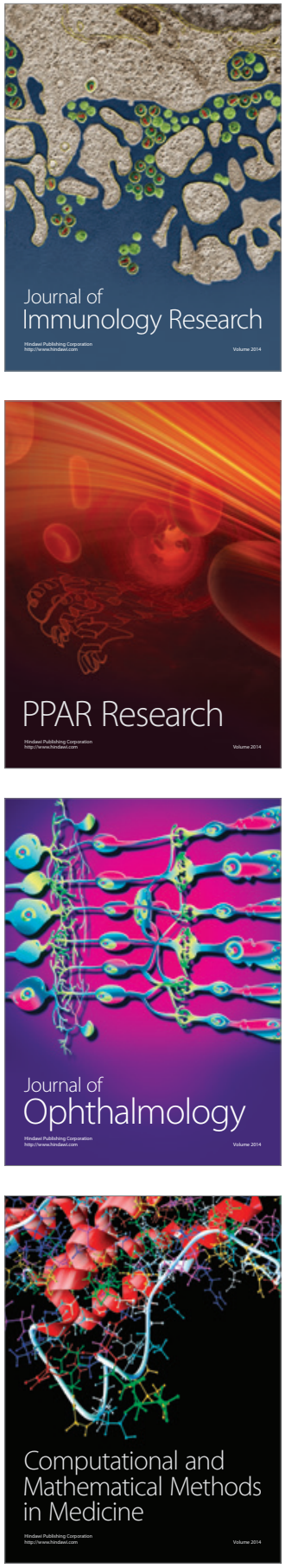

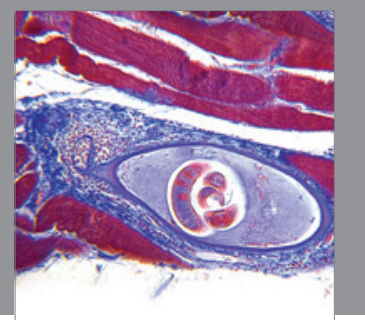

Gastroenterology

Research and Practice
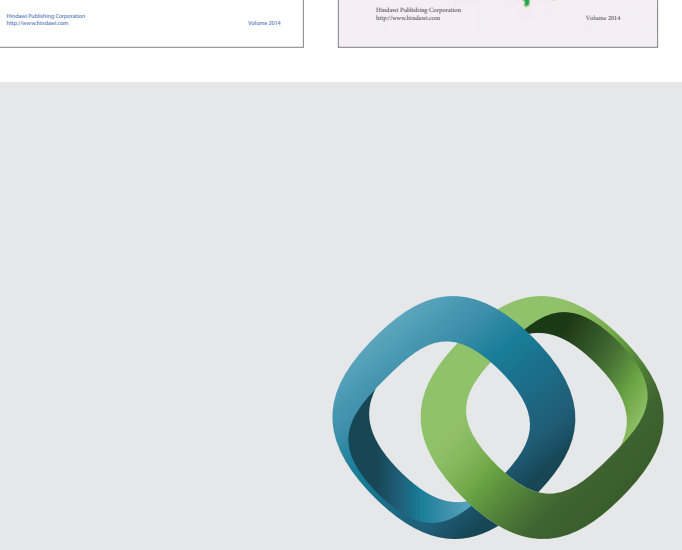

\section{Hindawi}

Submit your manuscripts at

http://www.hindawi.com
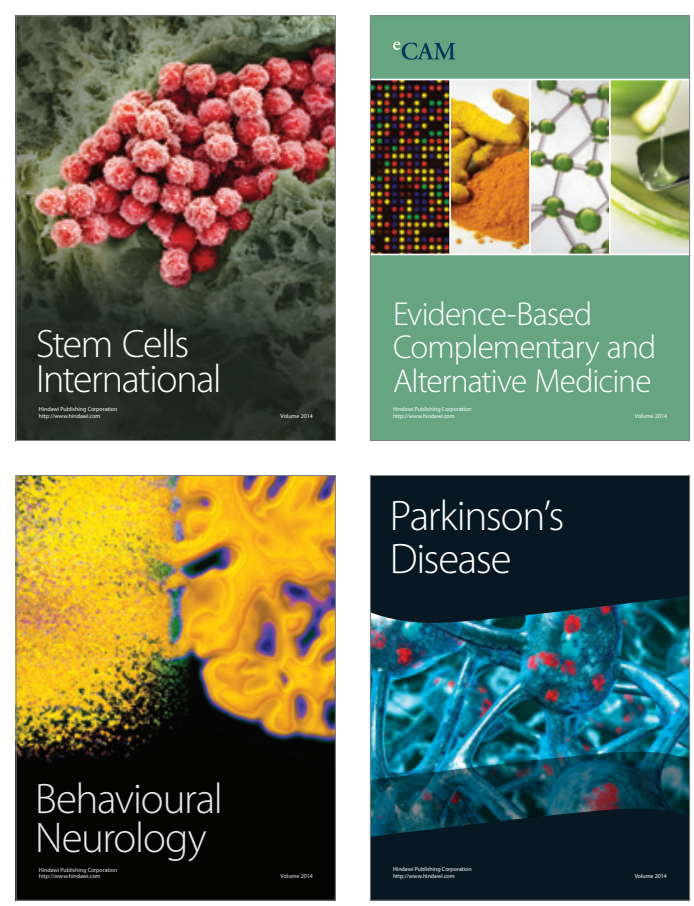

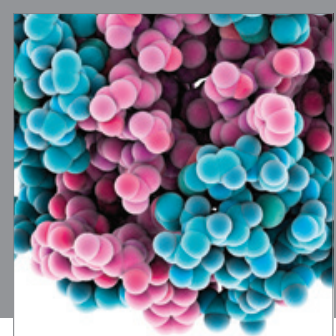

Journal of
Diabetes Research

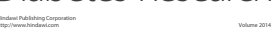

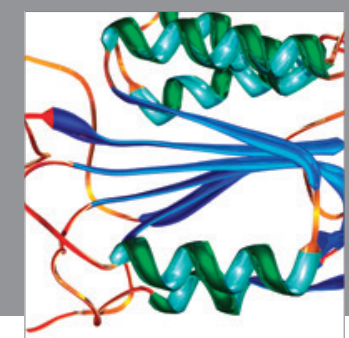

Disease Markers
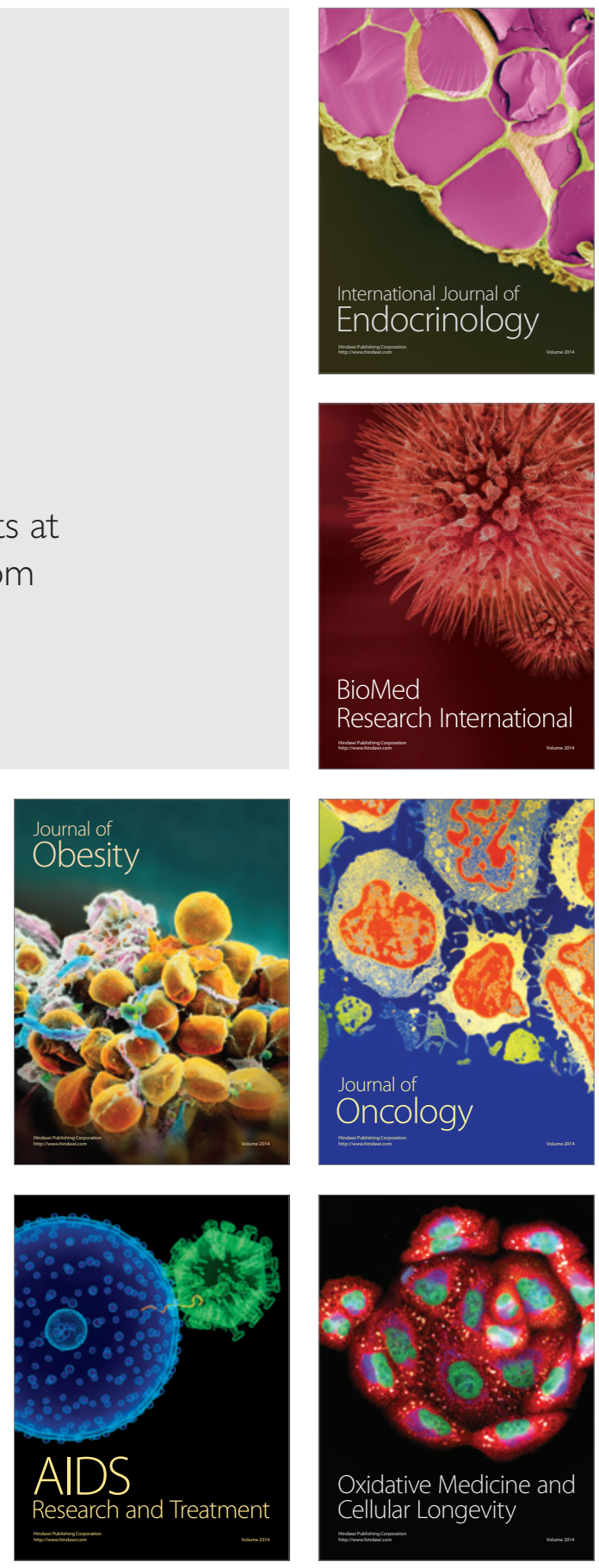